\title{
Fat-free/lean body mass in children with insulin resistance or metabolic syndrome: a systematic review and meta-analysis
}

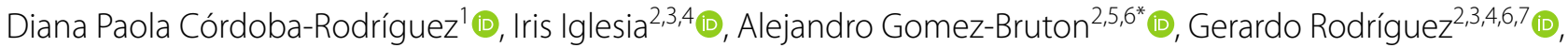

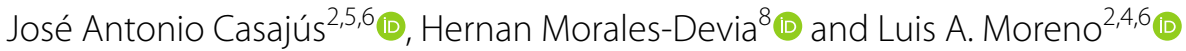

\begin{abstract}
Background: Lean / Fat Free Body Mass (LBM) is metabolically involved in active processes such as resting energy expenditure, glucose uptake, and myokine secretion. Nonetheless, its association with insulin sensitivity / resistance / glucose tolerance and metabolic syndrome remains unclear in childhood.
\end{abstract}

Methods: The current investigation aimed to examine the differences in fat-free mass /lean body mass according to the presence of insulin sensitivity/insulin resistance/glucose tolerance/metabolic syndrome in children.

A systematic search was carried out in Medline/PubMed, Embase, Scopus, Web of Science, and SciELO, covering the period from each database's respective start to 21 June 2021. Two researchers evaluated 7111 studies according to the inclusion criteria: original human studies, written in English or Spanish, evaluating fat-free mass/lean body mass in children and adolescents including both with and without insulin sensitivity/insulin resistance /glucose tolerance and metabolic syndrome and reported the differences between them in terms of fat free mass/lean body mass.

The results of the studies were combined with insulin sensitivity, insulin, resistance, glucose tolerance and metabolic syndrome. The standardized mean difference (SMD) in each study was calculated and combined using the randomeffects model. Heterogeneity between studies was tested using the index of heterogeneity $\left(I^{2}\right)$, leave-one-out sensitivity analyses were performed, and publication bias was assessed using the Egger and Begg tests.

Results: Finally, 15 studies which compared groups defined according to different glucose homeostasis criteria or metabolic syndrome out of 103 eligible studies were included in this systematic review and 12 studies in the metaanalysis. Meta-analysis showed lower fat-free mass/lean body mass percentage in participants with insulin resistance/ glucose tolerance/metabolic syndrome (SMD $-0.47 ; 95 \% \mathrm{Cl},-0.62$ to -0.32 ) while in mass units (kg), higher values were found in the same group (SMD, $1.01 ; 95 \% \mathrm{Cl}, 0.43$ to 1.60$)$.

Conclusions: Our results identified lower values of fat-free mass/lean body mass (\%) in children and adolescents with insulin resistance/glucose tolerance/metabolic syndrome and higher values of fat-free mass/lean body mass when these are expressed in $\mathrm{kg}$. The evidence of the impact of lean mass on children's glucose homeostasis or metabolic syndrome is limited, so future studies research should focus on explaining the effect of fat-free mass/lean body mass on different metabolic outcomes. Moreover, it may be interesting to evaluate the quality (muscle density) or functional (muscle strength) outcomes in addition to both absolute $(\mathrm{kg})$ and relative (\%) values in future studies.

\footnotetext{
*Correspondence: bruton@unizar.es

${ }^{2}$ Growth, Exercise, Nutrition and Development (GENUD) Research Group,

Universidad de Zaragoza, Zaragoza, Spain

Full list of author information is available at the end of the article
} original author(s) and the source, provide a link to the Creative Commons licence, and indicate if changes were made. The images or other third party material in this article are included in the article's Creative Commons licence, unless indicated otherwise in a credit line to the material. If material is not included in the article's Creative Commons licence and your intended use is not permitted by statutory regulation or exceeds the permitted use, you will need to obtain permission directly from the copyright holder. To view a copy of this licence, visit http://creativecommons.org/licenses/by/4.0/. The Creative Commons Public Domain Dedication waiver (http://creativeco mmons.org/publicdomain/zero/1.0/) applies to the data made available in this article, unless otherwise stated in a credit line to the data. 
The systematic review was prospectively registered at PROSPERO (registration number CRD42019124734; available at: http://www.crd.york.ac.uk/prospero [accessed: 05 April 2019]).

Keywords: Body composition, Insulin resistance, Metabolic syndrome, Infant, Child, Adolescent

\section{Key notes}

- Our findings indicate a lower percentage of fat-free/ lean body mass in participants with insulin resistance/glucose tolerance/metabolic syndrome, while higher values were found when expressed in $\mathrm{kg}$.

- The heterogeneity between the studies, should be considered when analyzing the results.

- The evidence on the impact of lean mass on glucose homeostasis in children is limited.

\section{Background}

Insulin resistance (IR) is defined as the reduction of the tissue's response to insulin action, and it is the opposite of insulin sensitivity (IS) [1]. Insulin resistance is significant in public health. Its persistence over time and its tendency to progress clinically are the first stages of the development of Type 2 diabetes [2]. Currently, the fluctuations of IR prevalence in children and adolescents range from $2.2 \%$ in those with a healthy weight to $10.8 \%$ in those with obesity [3]. Insulin resistance is recognized as a central component of metabolic syndrome (MetS) [4], characterized by central obesity and, at least, two of the following components: high blood pressure (BP), high triglycerides (TG), reduced HDL cholesterol (HDL-C), and elevated fasting plasma glucose (FPG) $[5,6]$. Metabolic syndrome's relevance to future health is its relationship with the development of Type 2 diabetes and cardiovascular diseases [6].To date, defining MetS's prevalence in children has been challenging, given the different existing criteria described in the literature [6]. In a recent systematic review published by Sharma et al. [3], the prevalence of MetS in children and adolescents varied from 3.4\% in normal-weight to $29 \%$ in the group with obesity.

Metabolic syndrome is associated with obesity. This situation is concerning because the number of children with obesity worldwide is expected to reach 250 million in 2030 [7]. The most widely used tools for detecting obesity and its cardiometabolic complications in children and adolescents is body mass index (BMI=Weight/ Height ${ }^{2}, \mathrm{~kg} / \mathrm{m}^{2}$ ). However, the BMI presents a critical limitation; it is not able to differentiate between body fat mass (FM) and fat-free body mass (FFM) [8]. Traditionally, most of the research in the field of metabolic complications associated with obesity in children has focused on evaluating body fat because of its strong association with cardiometabolic risk [9-12]. It is important to note that children with obesity, defined by BMI, have shown not only an increased FM but also a higher FFM $[13,14]$.

FFM is also an essential component of body composition. It represents approximately $80 \%$ of the body weight, including bones and lean body mass (muscles, extracellular water, nerve tissue, and other cells that are not adipocytes or fat cells) [15]. Fat-free/lean body mass (LBM) is involved metabolically in active processes such as resting energy expenditure, glucose uptake, and myokine secretion, which improve insulin sensitivity and stimulate lipolysis [16]. Currently, how high levels of body fat are associated with increased insulin resistance, MetS, dyslipidemia, and Type 2 diabetes is clear; meanwhile, the effects of LBM in some outcomes from a metabolic point of view are unclear [17]. In 2016, a review by Perreault et al. [18] concluded that the evidence on the mechanisms that link FFM and glucose homeostasis is currently limited, probably because studies have been carried out mainly in adults when the metabolic complications have already been established. Therefore, the primary objective of this systematic review and meta-analysis was to examine the possible differences in FFM/LBM in children with and without IS/IR, or glucose tolerance (GT) or MetS.

\section{Methods}

\section{Data sources and search strategy}

This review was carried out following the guidelines for systematic reviews and meta-analyses (PRISMA) [1921]. It was registered in the international database of prospectively registered systematic reviews (PROSPERO; http://www.crd.york.ac.uk/prospero) with the registration number CRD42019124734.

The search was carried out in the following databases: Medline/Pubmed (National Library of Medicine of the USA); Embase (Elsevier); Scopus (Elsevier); Web of Science [Core Collection / SciELO Science Citation Index] (Clarivate Analytics), and SciELO.org (FAPESP / CAPES / CNPq / Virtual Health Library / BIREME / Support Foundation to the Federal University of São Paulo-FapUnifesp).

The keywords used for the search (body composition, LBM, FFM, lean mass, lean tissue mass, lean body 
weight, skeletal muscle mass, muscle mass, fat-free mass index (FFMI), skeletal muscle mass index, muscle mass index, IS, IR, GT, metabolic syndrome $x$, MetS, infant, child, adolescent, and adolescence), were validated in $\mathrm{MeSH}$ (National of Library of Medicine of the USA controlled vocabulary thesaurus used for indexing articles for PubMed) and Emtree (controlled vocabulary thesaurus for biomedicine and life science for Embase). In addition, for these two databases (Medline/Pubmed and Embase), as well as for the others (Scopus, Web of Science [Core Collection and SciELO Citation Index], and SciELO.org), we used free terms or descriptors (keywords and phrases). These terms were searched under specific field codes in the title, abstracts, and keywords (depending on the search engine characteristics used) to retrieve most of the literature on the topic with terms not classified in the thesaurus. For our Medline/Pubmed and Embase searches, we added a highly sensitive filter to identify human studies.

For information retrieval, we applied an advanced search for each database using Boolean operators and wildcards, according to the characteristics and filters that each source provided for the queries. A search strategy was proposed that contemplated the grouping of related key terms through the "OR" operator and the crossings between the sets of words determined with the "AND" operators; within each set of terms, the corresponding wildcards were used; the asterisk character $\left(^{*}\right)$ as a truncation option and quotation marks ("), for a slightly more exact search of the phrases.

The search strategies were reviewed by another highlevel information retrieval specialist prior to execution using the PRESS checklist [22], and are described in Tables S1 and S2.

\section{Inclusion criteria}

We included studies that (1) evaluated children and adolescents aged 0 to 18 , with and without IS, IR, GT, and MetS; (2) evaluated body composition, namely, LBM, FFM, LM, lean tissue mass, skeletal muscle mass, muscle mass, skeletal muscle mass index, muscle mass index and FFMI, and reporting the differences that included both with or without IS, IR, GT, and MetS; (3) evaluated the results of IS and/or IR, GT, and MetS, including HDL-C, blood pressure, glucose, waist circumference, triglycerides, and insulin; (4) have one of the following study designs: cross-sectional study, case-control, observational study, or randomized controlled trial study design; (5) were published in peer-reviewed journals; (6) conducted studies in humans; (7) conducted studies published in English or Spanish, and (8) conducted studies published up to 21 June, 2021.
Automatic alerts for each database were established to provide weekly updates of new literature until June 2021.

Reference lists of included articles were manually screened to identify additional studies.

\section{Exclusion criteria}

We excluded (1) studies in children having diseases other than IS, IR, GT, and MetS; (2) studies without information regarding FFM/LBM and IS/IR/GT/MetS in children or adolescents, (3) studies in which FFM/LBM for the whole body or subtotal body were not available; (4) studies in adults and animals, and (5) those presented in languages other than Spanish or English.

\section{Search results}

Once executed search strings, exported the information from each database was in bibliographic management formats (Pubmed format [Medline/Pubmed], RIS (Embase, SciELO), CSV (Scopus), and CIW (Web of Science [Core Collection / SciELO Citation Index]). The text files were saved in folders and consolidated through a desktop application used for text mining called VantagePoint - VP (Search Technology Inc. 2020); with VantagePoint - VP we removed the duplicate references from the debugging of diacritics, spaces, and special characters, then we removed in phases the duplicates (by title, by abstract, by DOI). The de-duplication method used is one of the many procedures used by information professionals, being systematic, rigorous, and reproducible Bramer [23]. The search returned a total of 7111 potentially eligible articles. Two reviewers (DC and II) independently examined each publication for possible inclusion based on title, abstract, and full text, according to the inclusion and exclusion criteria.

The discrepancies among the reviewers were resolved by consensus. The arbitration of a third reviewer was used for the unresolved discrepancies (AGB).

\section{Data extraction}

Independently, two of the authors (DC and II) extracted data from each study, including the author, study date, study design, location, inclusion and exclusion criteria, participant data, methodology used to evaluate FFM/ LBM and results. This information was recorded in a file developed with Microsoft Excel ${ }^{\circledR}$, which was previously tested by the authors.

\section{Outcome assessment}

As primary results, the means $(\mathrm{M})$ and standard deviations (SD) of weight and/or height and/or FFM and/or LBM were registered for each group. If this information was not available in the original paper $(n=11$, including [24-34], we contacted the corresponding authors to 
obtain the desired information. Four of them [26, 28, 29, 34 responded. In the studies by Gonzalez-Gil et al. and Rodríguez-Rodríguez et al. [24, 27], the mean values (M) and standard deviations (SD) were calculated from the first quartile, median, third quartile, and sample size values, following Wan's [35] guidelines.

As secondary results, all those outcomes that were associated with FFM/LBM, such as lean-fat ration, irisin concentration, leptin, and LBMI-Z were registered.

\section{Quality assessment}

The analysis of the studies' quality was performed by two of the authors (DC and II) independently, using the following tools: 1) for cross-sectional studies, the BSA Medical Sociology Group quality evaluation tool [36], 2) for longitudinal studies, the scale created by Tooth et al. [37], 3) for clinical trials, the Cochrane Collaboration's tool [38]. The results of the quality assessment are shown in Additional file 1: Tables S3, S4, and S5. Quality was rated as high, moderate, low, or very low according to the GRADE (Grading of Recommendations Assessment, Development and Evaluation) criteria [39]. Summary of findings table were constructed using GRADE pro GDT (GRADEpro Guideline Development Tool [Software], McMaster University, 2020 [developed by Evidence Prime Inc]) [40].

\section{Statistical analysis}

For the data analysis, we used Review Manager 5.4.1 (The Nordic Cochrane Centre, The Cochrane Collaboration, Copenhagen, Denmark) Software to calculate the standardized mean difference (SMD) with 95\% confidence intervals $(\mathrm{CI})$. The standardized mean difference for continuous data (FFM/LBM (kg) or (\%)) in each study was calculated and combined using the random-effects model (DerSimonian and Laird approach). In the studies in which there was a double comparison, obese vs. obese and normal weight vs. obese, both comparisons were included in the meta-analysis.

Positive effect sizes indicated higher FFM/LBM $(\mathrm{kg})$ or (\%) in individuals with IS/IR/GT/MetS compared to individuals without IS/IR/GT/MetS. Negative effect sizes indicated lower FFM/LBM $(\mathrm{kg})$ or (\%) in individuals with IS/IR/GT/MetS compared to individuals without IS/IR/ GT/MetS.

Heterogeneity between trial results was tested using the heterogeneity index $\left(\mathrm{I}^{2}\right)$ whose thresholds for interpretation are $<25 \%$, low heterogeneity; 50 to $75 \%$ may represent moderate heterogeneity; $>75 \%$ may represent high heterogeneity [41]. The $p$-value associated with the studies' heterogeneity was calculated, indicating a nonsignificant result as the absence of heterogeneity. Leaveone-out sensitivity analyses were performed to assess the influence of outliers in FFM/LBM (\%) and FFM/LBM (kg) using Open Meta [Analyst] software.

Publication bias was assessed by Egger's test following the indications provided by Peters et al. [42]. Additionally, the Begg and Mazumdar test was applied to measure asymmetry in funnel plots [43].

\section{Results}

Finally, the following 103 articles were selected: [24-34, 44-135] after the evaluation of the full texts, 78 were excluded for the following reasons: (1) the design of the studies did not meet the inclusion criteria defined for this review [44-46, 48-53, 55-57, 59-61, 65, 66, 68-73, 79, $81,84,86,88-91,97,100-104,106,108,110,112-117$, 119-122, 124-132, 134, 135] (2) the studies did not present an evaluation of whole body FFM/LBM, these were $[47,54,58,62-64,67,74-78,80,82,83,85,92-96,105$, $107,109,111,123$ ] and (3) another language [87] (Fig. 1).

\section{Characteristics of the included studies}

This review includes the results of 15 studies. Eleven of them [24, 25, 27, 29, 30, 32-34, 98, 99, 118] were cross-sectional studies (CS). One [31] was a longitudinal study, and three $[26,28,133]$ were clinical trials (CT) (Fig. 1), which included a total of 5642 children (51.8\% boys). The information included in this systematic review and meta-analysis corresponds to the baseline data for the longitudinal studies and clinical trials to make them suitable to compare or combine in this systematic review.

Regarding the quality assessment, ten (90.9\%) of the cross-sectional studies [24, 25, 27, 29, 32-34, 98, 99, 118] received a moderate overall rating. Weiss et al. [30] had a high overall rating (9.1\%), see Additional file 1: Table S3. According to the scale by Tooth et al. [37], the longitudinal study [31] had a low score (13/33), see Additional file 1: Table S4. According to the Cochrane Collaboration's tool [38] for assessing risk, the three clinical trials $[26,28,133]$ presented bias risk. However, it is unlikely for this review that it affected the results because the included information corresponds to the baseline data before the intervention took place (Additional file 1: Table S5). Quality of evidence across studies was evaluated for each outcome using the GRADE approach [39]. A summary of findings table is presented in Additional file 1: Table S6.

\section{Participants sample size, country, and age}

The sample sizes of the studies included in this review ranged from $n=28$ to $n=3004$ participants [30, 34]. Regarding the countries where the studies were developed, five $[25,30,33,34,98]$ were carried out in the USA, two $[31,32]$ in Italy, and two $[26,28]$ in Brazil. One study 


\section{Identification of studies via databases and registers}

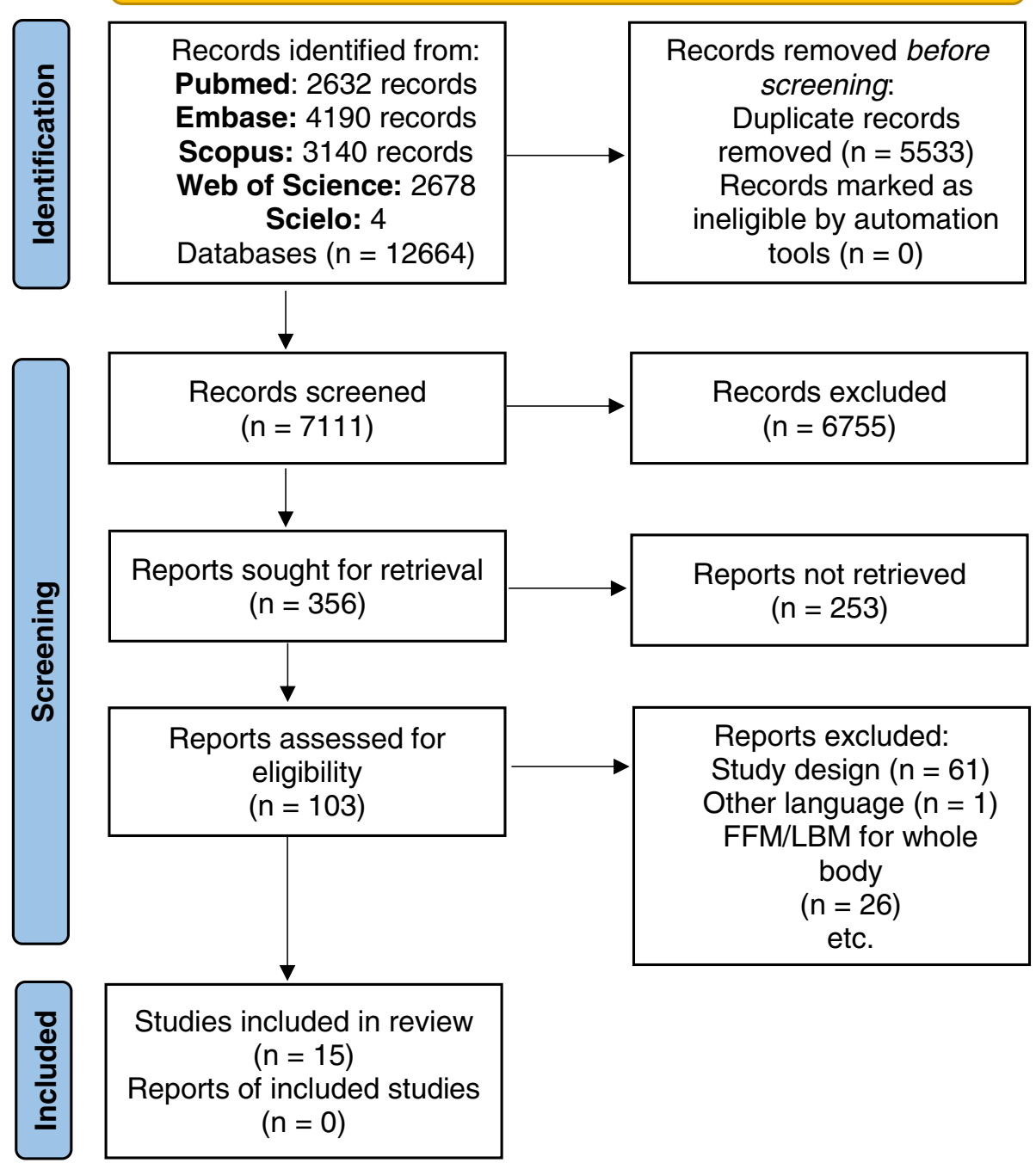

Fig. 1 PRISMA 2020 flow diagram for new systematic reviews which included searches of databases and registers only. From: Page MJ, McKenzie JE, Bossuyt PM, Boutron I, Hoffmann TC, Mulrow CD, et al. The PRISMA 2020 statement: an updated guideline for reporting systematic reviews. BMJ 2021;372:n71. doi: https://doi.org/10.1136/bmj.n71. For more information, visit: http://www.prisma-statement.org/

was performed in Mexico [24], Spain [27]; Chile [29]; France [133]; Iran [99]; and Turkey [118].

The age of the participants ranged from 5.2 to 19 years.

\section{Maturation stage}

Ten studies $[25,26,28,30-33,98,99,133]$ provided information on the methodology used for the assessment of the maturation stage; the Tanner scale was the method most widely used. Of the population referred to in these studies, $28.7 \%(n=349)$ were in Tanner I stage, that is, $[30-33,98,99]$ and $73.3 \%(n=959)$, in Tanner stages from II to V, namely, [25, 26, 28, 30, 32, 33, 98, 99, 133].
FFM/LBM measurement techniques

There are several body composition techniques available for the estimation of FFM/LBM in infants, children, and adolescents, including anthropometric measurements, bioelectrical impedance analysis (BIA), air-displacement plethysmography (ADP), dual-energy X-ray absorptiometry (DXA), computerized tomography (CT), magnetic resonance imaging (MRI), and ultrasound techniques [136]. In this review, one $(n=443)$ study [27] used anthropometric measurements. Three $(n=280)$ studies $[24,99$, $118]$ used BIA. Eight studies $(n=4640)[25,29-32$, $34,98,133]$ used DXA, and three $(n=279)$ studies, 
$[26,28,33]$ used air displacement plethysmography (BOD-POD).

Seven studies [28-30, 32-34, 98] registered LM, LBM, or lean tissue mass, which refers to the fat-free and bone mineral-free component, including muscles, skin, tendons, and connective tissues [137]. Seven studies [24$27,31,118,133$ ] expressed the results in terms of FFM, defined as the sum of muscle mass, bones, internal organ non-adipose components, and extracellular fluid [138]. One study expressed the results in terms of muscle mass [99].

Regarding the used indices to assess FFM/LBM, from the 14 studies included in the review, three [28, 29, 33] described LBM or lean tissue mass (\%). Three studies $[30,33,98]$ described LBM or lean tissue mass $(\mathrm{kg})$. one study [34] described LBMI-Z, and another [32] described LBMI $\left(\mathrm{kg} / \mathrm{m}^{2}\right)$.

Regarding FFM, four studies [26, 27, 31, 118] described FFM (\%). Six studies [24-26, 31, 118, 133] described FFM $(\mathrm{kg})$ and, one study [118], FFMI.

Gonzalez-Gil et al. study [24] described lean-fat ratio calculated as the quotient of muscle mass $(\mathrm{kg})$ and fat mass $(\mathrm{kg})$ and $[24,99]$ muscle mass $(\mathrm{kg})$.

The results of the individual studies are presented in Tables 1, 2 and 3.

\section{Methodologies of glucose homeostasis measurement}

For glucose homeostasis, several tests exist to assess the in vivo action of insulin, involving model evaluations, glucose sensitivity studies, and insulin and glucose clamps. These are fasting plasma glucose (aFPG), fasting plasma insulin resistance (FPI), insulin resistance (IR), homeostatic model assessment (HOMA), quantitative insulin sensitivity check index (QUICKI), meal tolerance test (MTT), oral glucose tolerance test (OGTT), intraperitoneal insulin sensitivity test (IPIST), and intraperitoneal glucose tolerance test (IPGTT) [139]. However, the hyperinsulinemic-euglycemic clamp is the gold standard [140].

In this review, three $(n=366)$ studies $[24,98,99]$ examined glucose homeostasis using fasting plasma glucose. Two studies $(n=355)[25,98]$ used an oral glucose tolerance test (OGTT). Four $(n=3603)$ studies used other indices, such as the ratio of fasting glucose to fasting insulin (GF/IF); these were [31-34]. Eight $(n=1140)$ studies $[26-29,31,99,118,133]$ used the homeostasis model assessment insulin resistance index (HOMAIR). And, the quantitative insulin sensitivity check index (QUICKI) was used in three $(n=229)$ studies [26, 28, 31]. See Tables 1,2 and 3.

A study by Weiss et al. [30] used the euglycaemic hyperinsulinaemic and hyperglycaemic clamps, in which case, the term glucose tolerance was used $(n=28)$. See Table 2.

To summarize, three studies [27-29] investigated FFM/ LBM in children and adolescents using IR. Three [25, 30, 98 ] involved children and adolescents with GT problems, and nine [24, 26, 31-34, 99, 118, 133] involved children and adolescents with MetS.

\section{FFM/LBM differences according to IR, GT, or MetS}

When performing the meta-analysis, using the three metabolic conditions together, it was observed that individuals with IR/GT/MetS had lower FFM/LBM (\%) than those without IR/GT/MetS (SMD -0.47; 95\% CI, -0.62 to -0.32 ; Fig. 2A). The heterogeneity between the studies was moderate $\left(\mathrm{I}^{2}=73 ; p=0.001\right)$, According to the GRADE system, the certainty of the evidence was very low.

Figure 3A shows the analysis of FFM/LBM (kg) absolute values in the participants with or without IR/GT/ MetS. The group with IR/GT/MetS had a higher FFM/ LBM (kg) (SMD, 1.01; 95\% CI, 0.43 to 1.60) compared to the group without IR/GT/MetS. The heterogeneity was high $\left(\mathrm{I}^{2}=93 ; p=<0.001\right)$.

A sensitivity analysis was performed including only one comparison per study (obese vs. obese; excluding the obese vs. normal-weight comparison), the results were consistent; the group with IR/GT/MetS still had a higher FFM/LBM (kg) (MSD, 0.55; 95\% CI, 0.19 to 0.92) when compared to the group without IR/GT/MetS. High heterogeneity was found $\left(\mathrm{I}^{2}=81, p=<0.001\right)$. The quality of evidence for this outcome was low.

\section{FFM/LBM and insulin resistance}

In the meta-analysis (Fig. 2B), subgroup analysis results suggested a lower FFM/LBM (\%) in the group of participants with IR (SMD, -0.53 ; 95\% CI, -0.71 to -0.35 ) with high heterogeneity between studies $\left(\mathrm{I}^{2}=87 ; p<0.01\right)$. According to the GRADE system, the certainty of the evidence was very low.

Because each of the three included studies for the IR group used a different measurement technique. A subgroup analysis taking into account the used body composition device could not be performed.

Only the study by Sanches et al. [28] included data for FFM/LBM $(\mathrm{kg})$. Therefore, we were not able to perform a meta-analysis for this variable in IR children.

\section{FFM/LBM and GT}

We were not able to estimate the differences in the FFM/ LBM (\%) in individuals with or without GT because no studies reported FFM/LBM (\%) in this group. However, for FFM/LBM (kg), Fig. 3B shows that there were statistical significant differences in FFM/LBM $(\mathrm{kg})$ between 


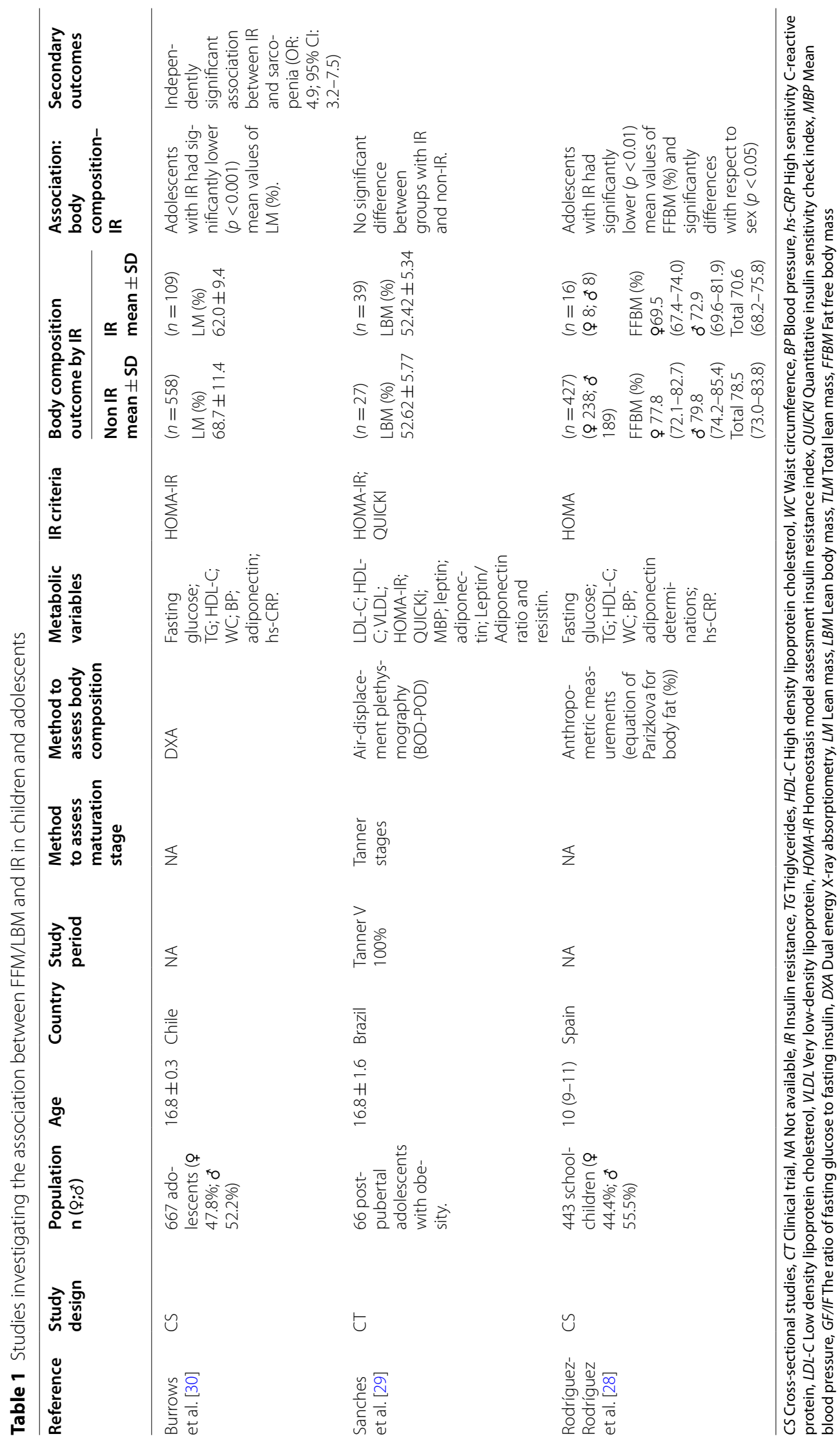




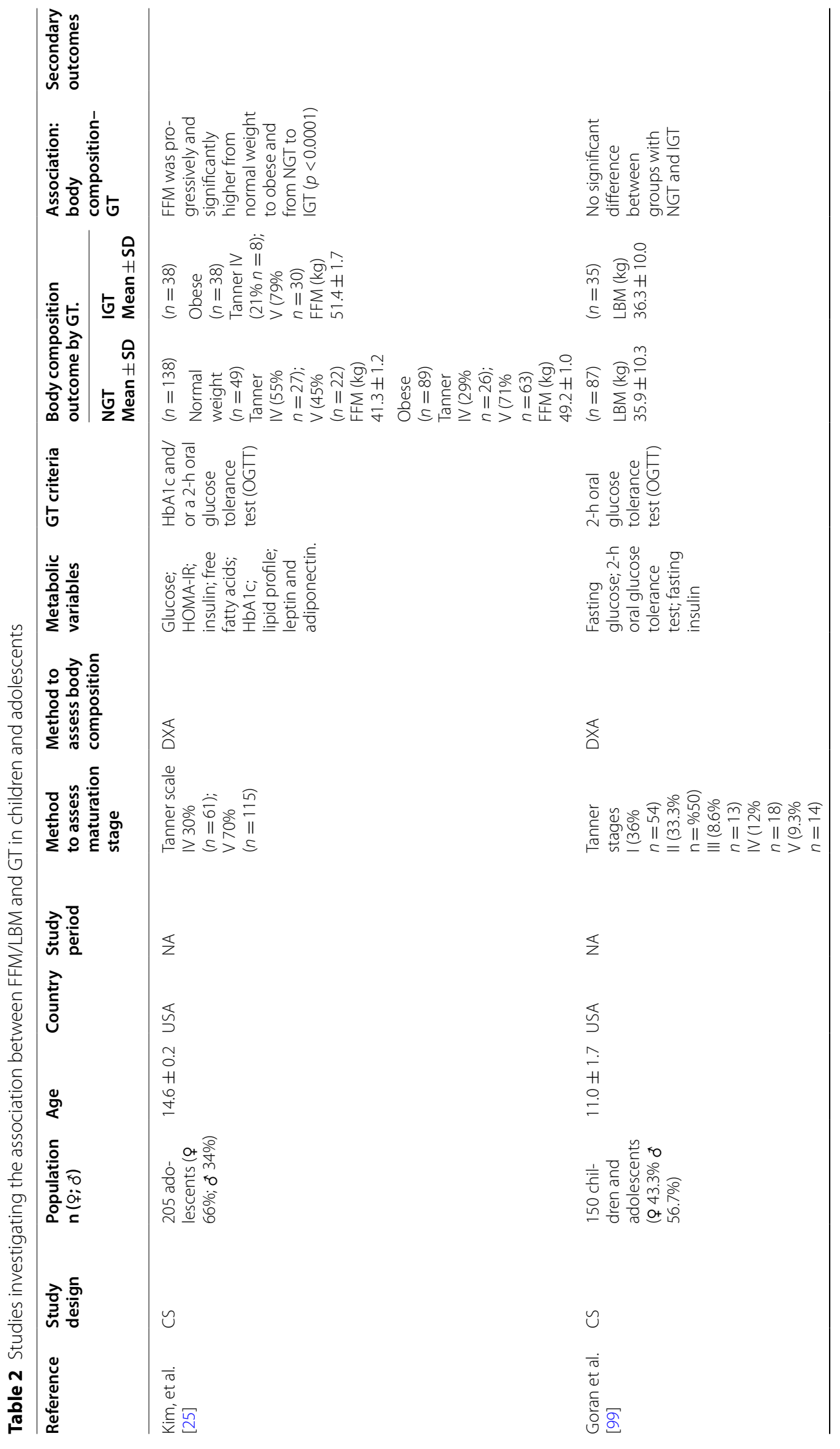




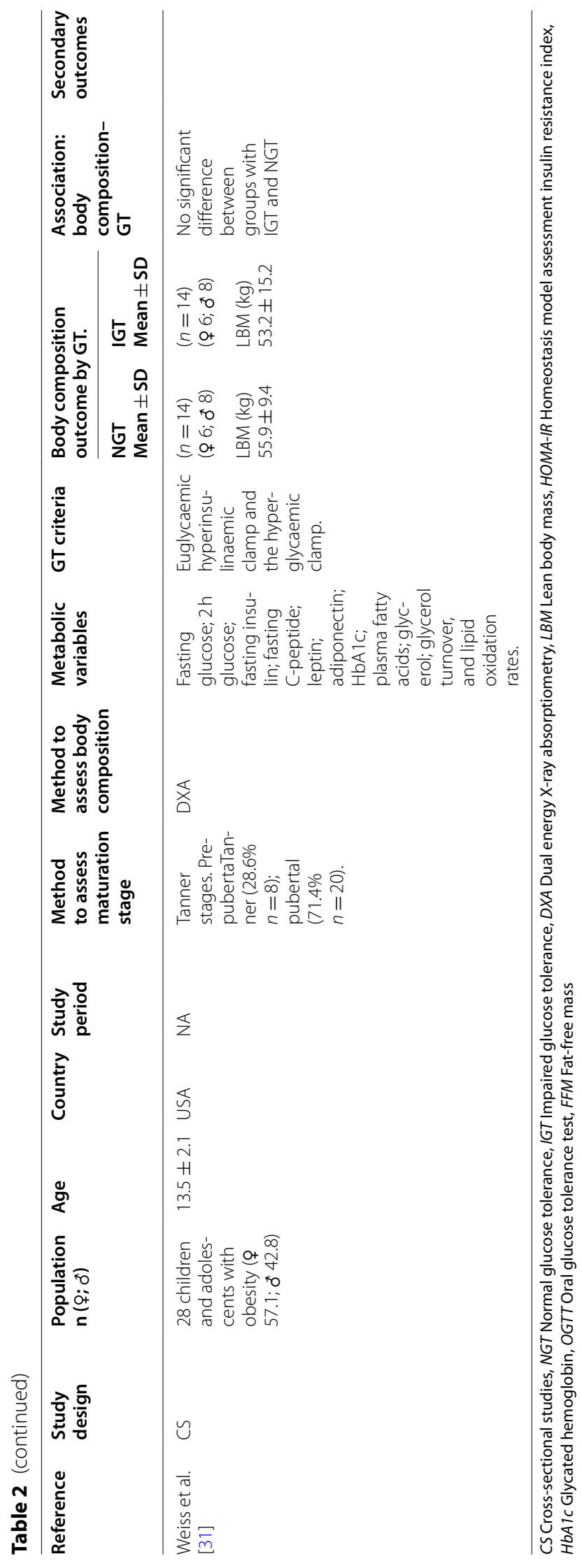




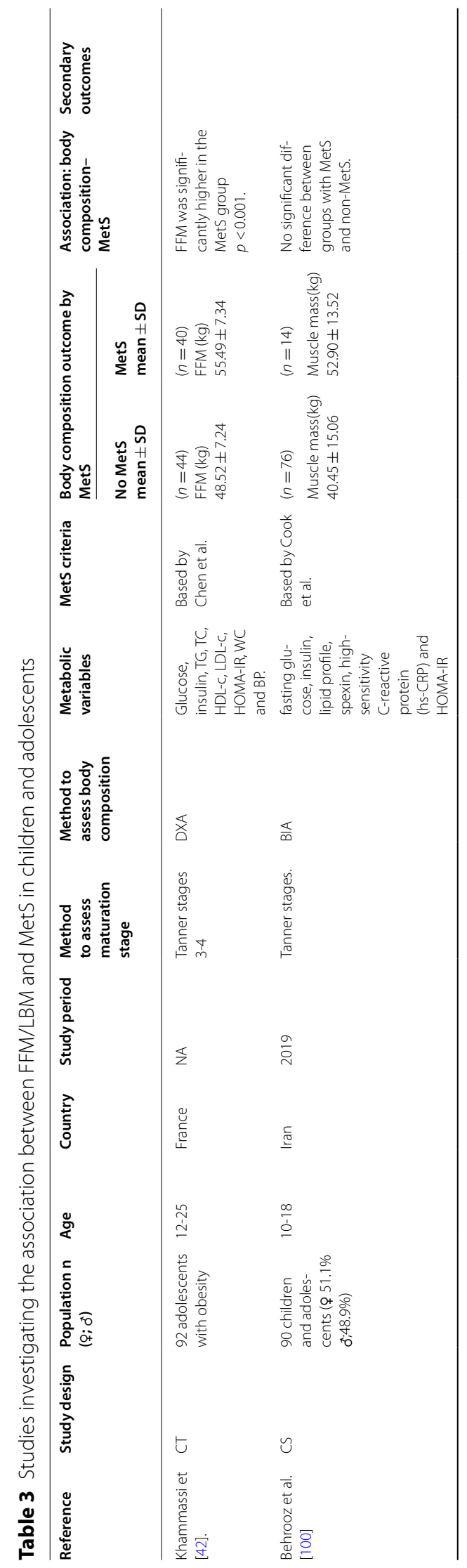




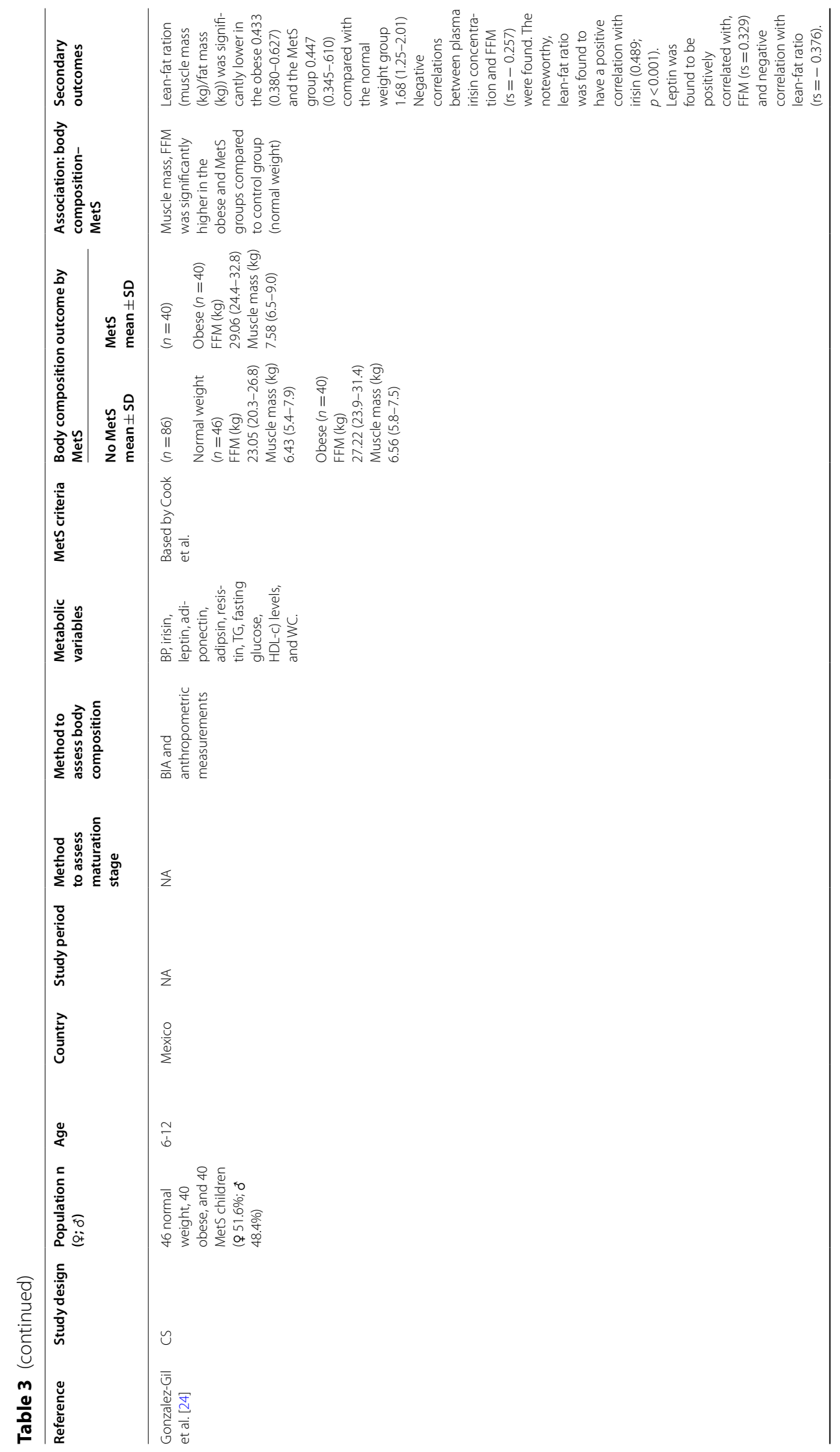




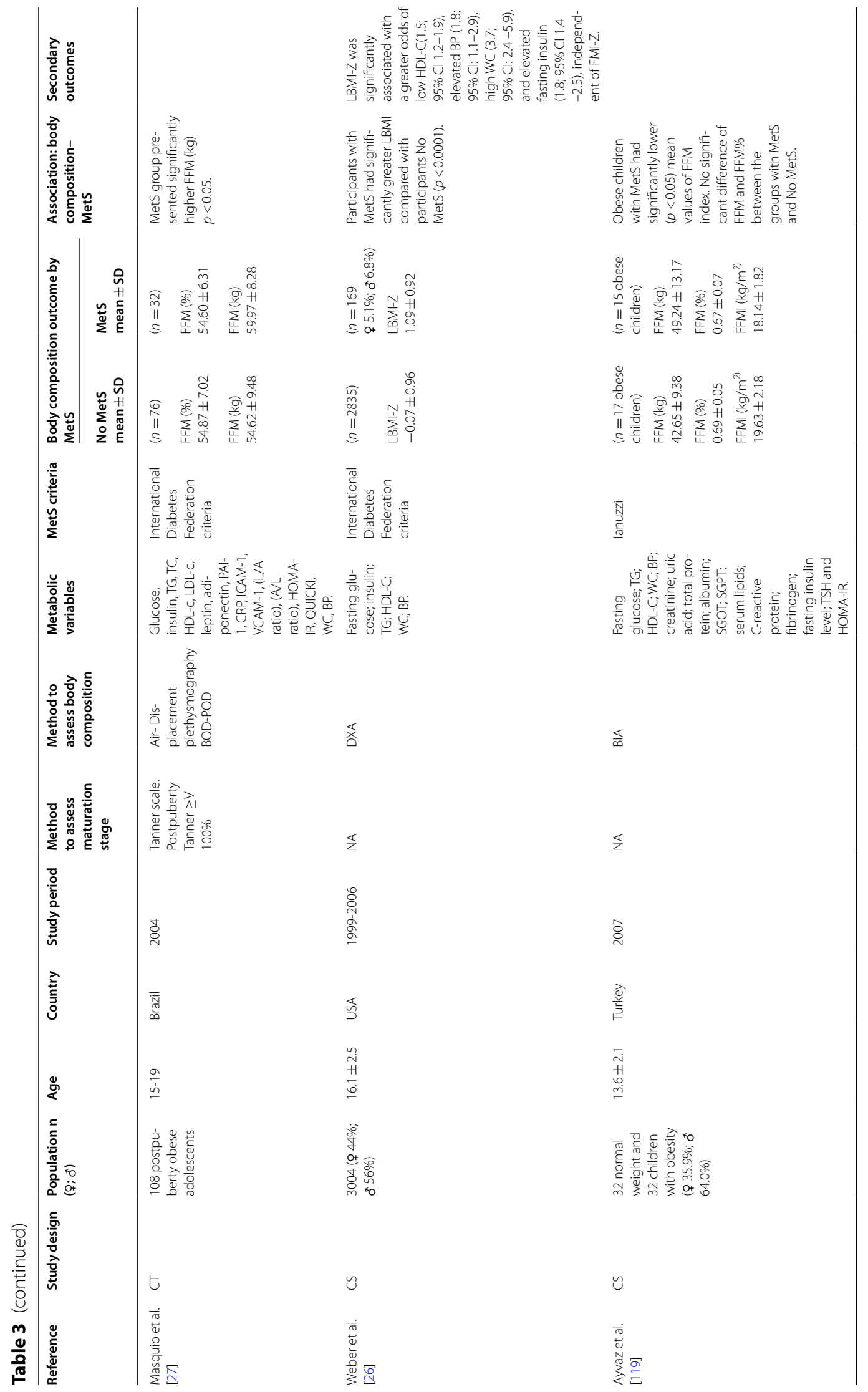




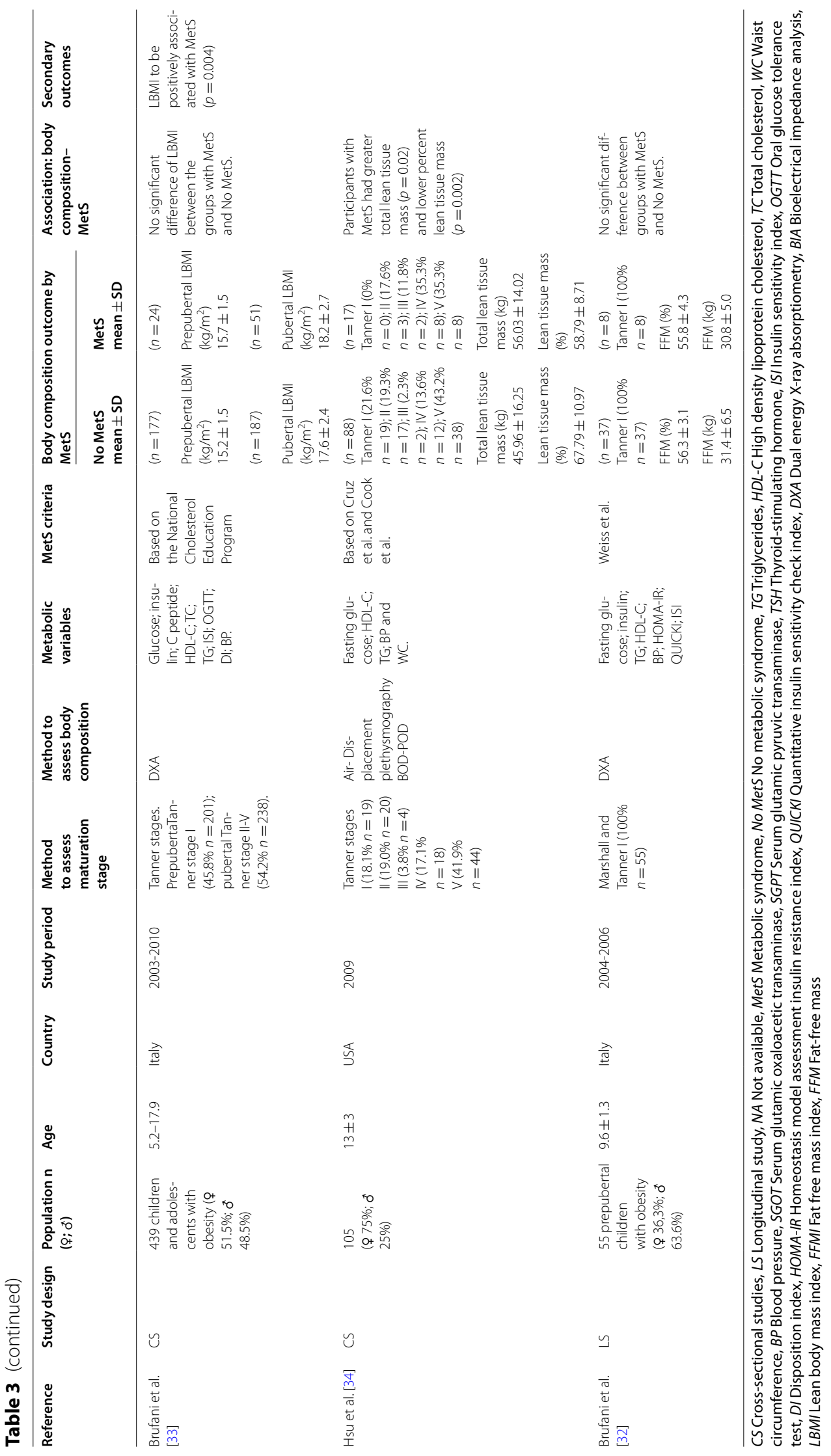



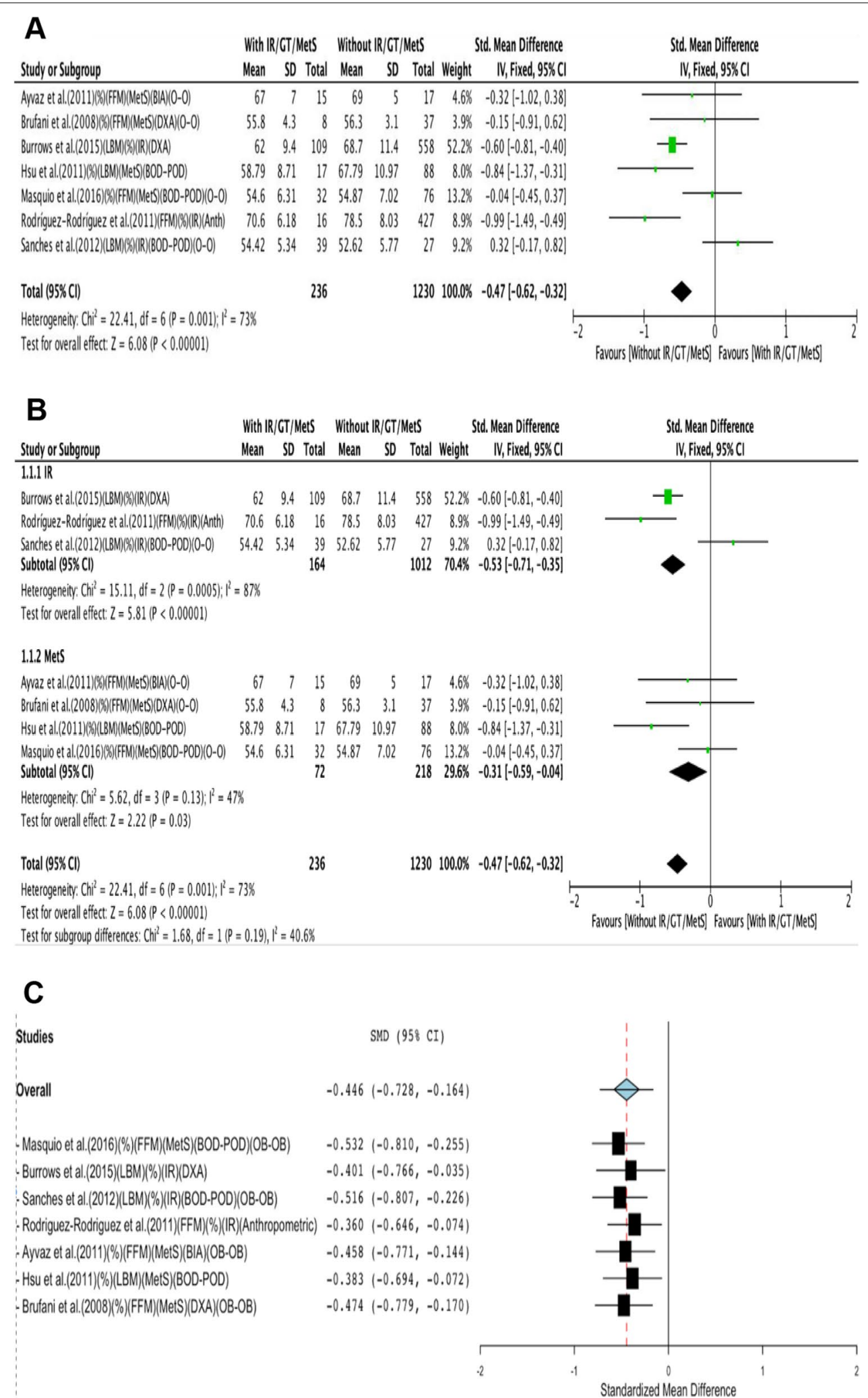

Fig. 2 Random-effects meta-analysis with IR/MetS or without IR/MetS on FFM/LBM (\%). a FFM/LBM (\%) b Subgroup analyses by diagnosis (group IR and group MetS). c Leave-one-out meta-analysis. Abbreviations: FFM, fat-free mass; LBM, lean body mass; IR, insulin resistance; MetS, metabolic syndrome 
both groups (SMD, 2.07; 95\% CI, 0.04 to 4.10), with high heterogeneity $\left(\mathrm{I}^{2}=98 ; \mathrm{p}<0.01\right)$. The results were not consistent when performing the analysis that included a comparison per study (obese vs. obese; excluding the obese vs. normal-weight comparison); there were no statistically significant differences between both groups (SMD, $0.54 ; 95 \% \mathrm{CI},-0.72$ to 1.81 ), and high heterogeneity $\left(\mathrm{I}^{2}=95 ; p<0.01\right)$. The quality of evidence for this outcome was very low.

\section{FFM/LBM and MetS}

In the meta-analysis (Fig. 2B), the results of the subgroup analysis showed that there were statistical significant differences in FFM/LBM (\%) between both groups (SMD, $-0.31 ; 95 \% \mathrm{CI},-0.59$ to -0.04$)$, with low heterogeneity $\left(\mathrm{I}^{2}=47 ; p=0.13\right)$ and the quality of evidence was very low.

Figure 3B shows the subgroup analysis for FFM/LBM $(\mathrm{kg})$ in the participants with or without MetS, suggesting higher values of FFM/LBM $(\mathrm{kg})$ in the group of participants with MetS (SMD, 0.62; 95\% CI, 0.36 to 0.88) with low heterogeneity $\left(\mathrm{I}^{2}=44 ; p=0.09\right)$. The quality of evidence for this outcome was low.

Regarding the analysis by subgroups, taking into account the type of device used to assess the FFM/LBM (kg), significantly higher FFM/LBM $(\mathrm{kg})$ values were found in the groups with MetS when evaluated with anthropometryBIA (SMD, 0.64; 95\% CI, 0.15 to 1.14; Fig. 3C) with moderate heterogeneity $\left(\mathrm{I}^{2}=63 ; p=0.07\right)$, BOD- POD (SMD, 0.60 ; $95 \% \mathrm{CI}, 0.271$ to 0.93 ; Fig. 3C) with low heterogeneity $\left(\mathrm{I}^{2}=0.0 ; p=0.89\right)$, and DXA (SMD, 1.49; 95\% CI, 0.21 to 2.78; Fig. $3 \mathrm{C})$ with high heterogeneity $\left(\mathrm{I}^{2}=97 ; p<0.01\right)$ and the quality of evidence was very low.

The results were consistent when performing the analysis including a comparison per study (obesity vs. obesity, excluding the obese vs. normal-weight comparison); higher values of FFM/LBM $(\mathrm{kg})$ were found in the group of participants with MetS (SMD, 0.44; 95\% CI, 0.21 to $0.68)$ with low heterogeneity $\left(\mathrm{I}^{2}=0 ; p=0.51\right)$ and the quality of evidence was low.

When performing the analysis, including a comparison per study (obesity vs. obesity, excluding the obese vs. normal-weight comparison), no significant differences were found between groups when measured using anthropometry-BIA and DXA.

\section{Sensitivity analysis}

A forest plot was conducted leaving one out of the total included studies for each combination as a sensitivity analysis. The effect size remained significant after the omission of each study from the meta-analysis (Figs. 2C and 3D).

\section{Publication bias}

No evidence of publication bias was found for studies measuring FFM/LBM (\%) (Begg's $p=1.000$; Egger's $p=0.681$ ). For the studies that included measurements of FFM/LBM $(\mathrm{kg})$, no evidence of publication bias was found according to the Begg test $(p=1.000)$, but we have obtained significant results of possible bias when the Egger test was used $(p=0.006)$, although the reduced number of included studies could limit this analysis.

To summarize, the meta-analysis showed lower FFM/ LBM values (\%) in participants with IR/GT/MetS. This situation can also be seen in the diagnostic subgroup analyses in the case of IR and MetS. Regarding FFM/ LBM behavior, when expressed in $(\mathrm{kg})$, the meta-analyses showed higher values in the group with IR/GT/MetS; this could also be evidenced in the subgroup analyses by diagnosis in the case of GT and MetS. Regarding the device used for its measurement, significant differences were found between groups with MetS when evaluated with anthropometry-BIA, BOD-POD and DXA. For IR, it was impossible to show the difference because the analysis by subgroups could not be performed, given the low number of studies included in this systematic review.

\section{Discussion}

To the best of our knowledge, this is the first systematic review and meta-analysis providing an overview of current scientific evidence regarding the possible differences between FFM/LBM in children with and without IR, glucose tolerance, or MetS.

Our systematic review and meta-analysis identified lower values of FFM/LBM (\%) in children and adolescents with IR/GT/MetS, and higher values of FFM/LBM when these are expressed in $\mathrm{kg}$. Considering that the percentage of LBM/FFM automatically decreases in proportion to increases in \% of body fat [141], it is likely that children and adolescents with IR/GT/MetS will present higher values of body fat and android fat (visceral fat) accumulation, as shown in adults [142]. This will eventually lead to lower values of FFM/LBM in proportion to the total body weight. This effect on glucose homeostasis could be entirely or largely due to the association between adiposity and insulin resistance, previously described in children [143].

(See figure on next page.)

Fig. 3 Random-effects meta-analysis with IR/GT/MetS or without IR/GT/MetS on FFM/LBM (kg). a FFM/LBM (kg) b Subgroup analyses by diagnosis (group GT and group MetS). c Subgroup analysis by a device (anthropometric measurements and BIA group and BOD-POD and DXA group). d Leave-one-out meta-analysis. Abbreviations: FFM, fat-free mass; LBM, lean body mass; IR, insulin resistance; GT, glucose tolerance; MetS, metabolic syndrome 


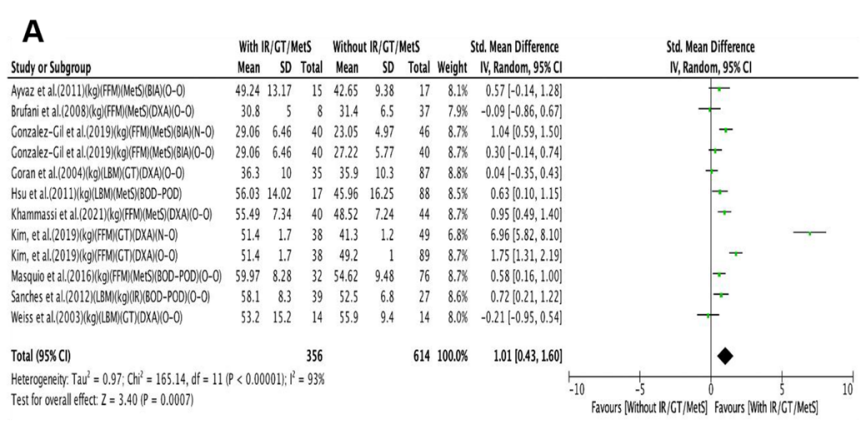

\section{B}

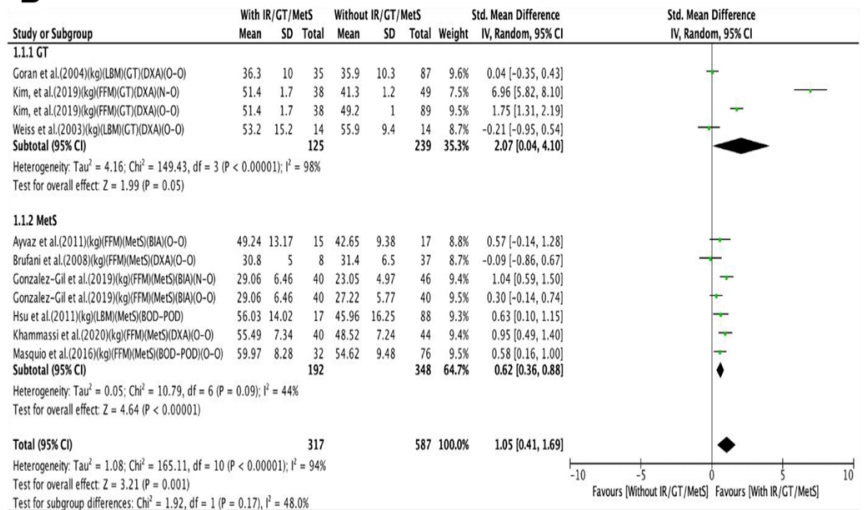

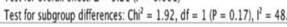

\section{C}

Sulyor os Suggoup

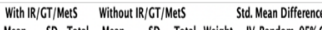

Std. Mean Difference
IV, Random, $95 \%$ CI

1.1.1. Anthropometric-8BA Nee Subgroup

Ulean SD Total Wean SO Total Weight N.Random, $95 \%$

$\begin{array}{lllllllll}49.24 & 13.17 & 15 & 42.65 & 9.38 & 17 & 8.8 \% & 0.571-0.14,1.22\end{array}$

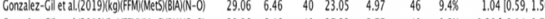

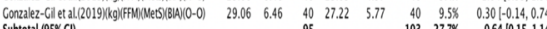

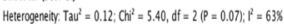

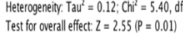

1.1 .2 BOD-POD

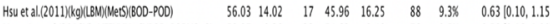

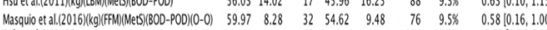

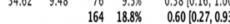

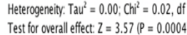

$1.130 \times A$

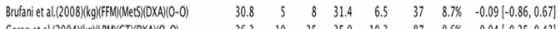

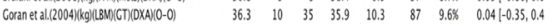

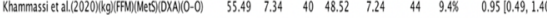

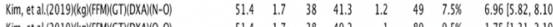

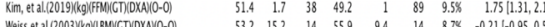

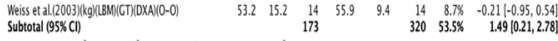

Heterogeneniy $7 \mathrm{~T}^{2}=2.45 ;$ Chi $^{2}=156$

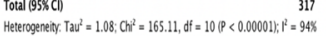

Test for orerall effect $z=3.21$ P $=0.001$

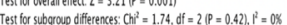

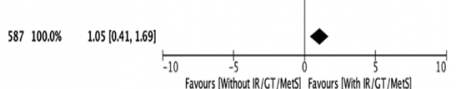

D

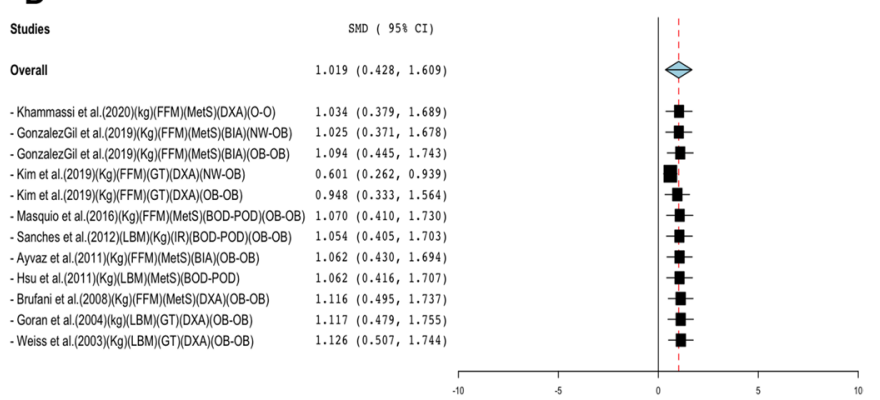

Fig. 3 (See legend on previous page.) 
In this review, two studies [27, 29] found that adolescents with IR had significantly lower FFM/LBM (\%). This could be due to the fact that FFM is a metabolically active tissue associated with insulin-stimulated glucose uptake in the postprandial state in humans, as well as greater insulin sensitivity [144], reduction in the accumulation of fat inside the muscle [145], and muscle secretory products or "myokines" that favor IS [16].

Furthermore, low muscle mass has been associated with cardiovascular risk factors, such as increased blood pressure, risk of abdominal obesity, and hypertriglyceridemia [122], as well as arterial stiffness [146] and low muscle fitness, which, in turn, has been independently associated with metabolic risk in children and adolescents [147].

Finally, this systematic review identified six studies that found higher levels of FFM/LBM/muscle mass in children with MetS or GT. Five $(n=3435)$ of them $[24,26,33,34,133]$ found higher levels in children with MetS, and one $(n=205)$ with glucose tolerance [25]. Other available studies have described higher levels of FFM/LBM in individuals with MetS. You et al. [148] found that in postmenopausal women, 50 to 70 years old, lean mass $(\mathrm{kg})$ was significantly higher $(p<0.05)$ in the group of women with higher HOMA-IR scores and MetS compared to those without MetS (44.4 \pm 0.9 ; $41.2 \pm 0.9$ ). Brochu et al. [142], in a study with 43 postmenopausal and sedentary women, found that women with metabolically abnormal obesity MAO (low IS) showed higher levels of LBM $(\mathrm{kg})$ than those who were metabolically healthy but obese (MHO) (43.8 \pm 5.5 ; $48.1 \pm 7.2[p<0.03])$. These findings are in line with our meta-analysis findings. People presenting these diseases generally have a higher weight and, consequently, higher absolute lean mass values. Nonetheless, as shown in this meta-analysis, relative values (\%) are generally similar or even lower, which, as stated above, represent not only the values on FFM/LBM but also the proportion of fat mass.

On the other hand, other studies have shown that increased muscle mass does not necessarily translate into better muscle quality or better physical performance in people with MetS. This is the case of the study developed by Mesinovic et al. [149] with overweight and obese older adults. They observed that people with MetS had lower muscle quality (muscle density and strength normalized to lean mass) despite having a higher FFM. The previous suggests that a higher FFM does not confer an advantage from a functional point of view. Similarly, the study carried out with 1050 adolescents participating in the Korean National Health and Nutrition Examination Survey found a lower handgrip-to-weight ratio in adolescents with metabolic syndrome [67].
The mechanisms underlying the association between FFM/LBM and IR, GT or MetS are not entirely clear. In the case of adults, it is attributed to the types of fibers (higher percentage of type II and type IIx muscle fibers) whose capillary density is reduced, which limits the transport of glucose to the muscles; as well as a reduced oxidative capacity and an increase in intramuscular fat storage [150]. However, more children-focused studies are needed to examine these mechanisms in the early stages of life.

\section{Limitations and strengths}

This systematic review and meta-analysis presents some limitations. The first one involves the different terms found in the literature to define both FFM and LBM [151] and IR, GT, and MetS [152], especially in pediatric populations.

The second is related to the investigations' population heterogeneity. Some of the studies focused on patients with obesity, while others included children and adolescents with both normal BMI and obesity, in different age ranges, maturation stages, grouping them by gender, or combining the two. Some presented heterogeneous methodologies for determining body composition. For instance, Rodríguez-Rodríguez et al. [27] used anthropometric measurements. Three others $[24,99,118]$ used BIA, three $[26,28,33]$ used ADP, and eight $[25,29-32$, $34,98,133]$ used DXA. The different used techniques could explain the differences in the results of fat mass and subsequently of lean mass, since, as shown in other studies [153, 154], these body composition methods are not interchangeable and can affect the results due to intra-instrument and inter-instrument variability. Factors related to the technician (that is, intra-operator and interoperator variability), factors related to the subject (that is, preparation of the subject as position and measurement schedule, among others) and even factors related to the environment (for example the temperature of the environment in the case of BIA) will influence results [137].

Thirdly, some studies [24-31, 33, 98, 133] used absolute or relative FFM/LBM measures ( $\mathrm{kg}$ and \%), which makes it difficult to compare the individuals of different sizes adequately, given that FFM varies with height, weight, and age, and FFM percentage decreases automatically in proportion to increases in \% body fat. Some studies [32, 34, 118] did show different indices using measures adjusted for height $\left(\mathrm{kg} / \mathrm{m}^{2}\right)$ or lean to fat ratio (muscle mass $(\mathrm{kg}) /$ fat mass $(\mathrm{kg})$ [24].

Furthermore, using absolute $(\mathrm{kg})$ or relative values $(\%$ or index) can generate different and even contradictory results. For instance, in the study developed by Masquio et al. [26], the MetS group presented a significantly higher 
FFM (kg); however, this difference was not significant when the analysis was performed as a percentage. In the study conducted by Ayvaz et al. [118], there were no differences reported in FFM (kg) and FFM (\%) between participants with MetS. However, when the results were presented as FFMI, it was found that children with obesity and MetS had lower FFMI values than those without MetS.

Other authors have recently also highlighted that the way of expressing FFM/LBM (absolute vs. relative values) greatly influences the direction of the association with metabolic health [150]. Further studies considering height adjusted indices to assess FFM/LBM are necessary [155].

Fourth, the selection bias of the patients who participated in the included studies may have influenced the present meta-analysis results. Besides, the publication bias could potentially have led to an underestimation of the pooled estimates.

Fifth, most of the studies included in this review did not investigate the association between FFM/LBM and IR/GT/MetS in children and adolescents as their primary objective, limiting the results presented here as they are not studies especially designed for this.

Sixth, this review did not include grey literature such as technical reports, conference proceedings, and doctoral theses, which could also prove helpful.

Seventh, in the different analysis, very few studies evaluated their effect; therefore, the results should be viewed with caution.

Eight, high heterogeneity was found in some of the performed meta-analysis. This could be due to the fact that we could not control the possible covariates (population enrolled, study design, methodologies for determining body composition and glucose homeostasis, maturation, nutritional status) that may explain this heterogeneity because of the low number of studies included, calling for caution in the interpretation of the results.

Lastly, the strength of the evidence is low due to the observational design of almost all included studies, and it was not possible to establish any causal relationship between FFM/LBM and IR/GT/MetS in children/adolescents. The certainty of the evidence was reduced to low and very low, mainly due to the inconsistency and imprecision of the included studies.

However, this study also has several strengths. As far as we know, this study is the first systematic review and meta-analysis that examines the differences in FFM/LBM according to the presence of IR/GT/MetS in children and adolescents. This review followed strict procedures to ensure the validity of the results (registered in the PROSPERO database, PRISMA protocol, two reviewers, quality evaluation of the studies, use of the GRADE system to rate the certainty of the evidence, the performance of a meta-analysis).
Based on the findings of this review, there are a number of considerations for future research in this area. It is necessary to define a criterion for the classification of MetS in children, given the different existing criteria in the literature. In addition, an attempt should be made to unify a unit of expression of the FFM/LBM since different expressions can lead to contrasting conclusions.

Finally, research studies should focus on explaining the effect of FFM/LBM on different metabolic outcomes, preferably involving representative population samples and robust body composition techniques to obtain a better understanding of such associations. Moreover, it may be interesting to evaluate the quality (muscle density), composition (accumulation of fat inside the muscle or intramuscular adipose tissue), or the functional results (relative strength) in addition to the absolute $(\mathrm{kg})$ and relative (\%) values in future studies. Additionally, further studies should evaluate those factors that during the prenatal period and early postnatal development can affect the results of FFM/LBM.

\section{Conclusion}

The main finding of this systematic review is that there is limited evidence on the impact of FFM/LBM on IS/ IR/GT/MetS in children and adolescents, and the available literature is contradictory. Furthermore, the way of expressing FFM/LBM influences the observed results on its association with IS/IR/GT/MetS. Our results indicate a lower percentage of FFM/LBM in participants with IR/ GT/MetS. At the same time, higher values were found when expressed in mass $(\mathrm{kg})$ units.

This research proposes a new study scenario that considers the effect of FFM/LBM on metabolic outcomes to explain the inconsistent association with obesity assessed using the BMI. This reinforces the routine assessing body composition in the pediatric population.

\section{Abbreviations}

IR: Insulin resistance; IS: Insulin sensitivity; MetS: Metabolic syndrome; BP. Blood pressure; TG: Triglycerides; HDL-C: HDL cholesterol; FPG: Fasting plasma glucose; BMI: Body mass index; FM: Fat mass; FFM: Fat-free mass; LBM: Lean body mass; GT: Glucose tolerance; FFMI: Fat-free mass index; HOMA-IR: Homeostasis model assessment-insulin resistance.

\section{Supplementary Information}

The online version contains supplementary material available at https://doi. org/10.1186/s12887-021-03041-z.

Additional file 1: Table S1. Search strategy for systematic reviews and systematic review protocols. Table S2. PRISMA-S Checklist. Table S3. Quality assessment of the included cross-sectional studies. Table S4. Quality assessment of the included longitudinal study. Table S5. Quality assessment of the included clinical trial. Table S6. Grading of Recommendations, Assessment, Development, and Evaluation (GRADE) summary of findings. Table S7. PRISMA 2020 for abstracts Checklist. 


\section{Authors' contributions}

DPCR searched for studies, agreed to inclusion and exclusion, extracted data, performed a meta-analysis, drafted the manuscript, revised and provided intellectual information in the final manuscript. II searched for studies, agreed to inclusion and exclusion, extracted data, drafted the manuscript, revised and provided intellectual information in the final manuscript. AGB performed the meta-analysis, drafted the manuscript, revised, and provided intellectual information in the final manuscript. GR drafted the manuscript, revised and provided intellectual information in the final manuscript. JAC drafted the manuscript, revised and provided intellectual information on the final manuscript. HMD designed the search strategies, performed the search in different databases, exported the information from each database in bibliographic management formats, performed the record deduplication processes, updated the searches, and reviewed the final manuscript. LAM drafted the manuscript, revised it, and provided intellectual input to the final manuscript. The author(s) read and approved the final manuscript.

\section{Funding}

We thank the Carolina Foundation Ph.D. Grants, which supported the first author in the production of this manuscript.

\section{Availability of data and materials}

All data generated or analyzed during this study are included in this published article [and its supplementary information files].

\section{Declarations}

Ethics approval and consent to participate

Not applicable.

\section{Consent for publication}

Not applicable.

\section{Competing interests}

The authors declare that they have no competing interests.

\section{Author details}

${ }^{1}$ Departamento de Nutrición y Bioquímica, Facultad de Ciencias, Pontificia Universidad Javeriana, Bogotá, DC, Colombia. ${ }^{2}$ Growth, Exercise, Nutrition and Development (GENUD) Research Group, Universidad de Zaragoza, Zaragoza, Spain. ${ }^{3}$ Instituto Agroalimentario de Aragón (IA2), Instituto de Investigación Sanitaria Aragón (IIS Aragón), Zaragoza, Spain. ${ }^{4}$ Red de Salud Materno Infantil y del Desarrollo (SAMID), Instituto de Salud Carlos III, Madrid, Spain. ${ }^{5}$ Faculty of Health and Sport Sciences (FCSD), Department of Physiatry and Nursing, University of Zaragoza, Zaragoza, Spain. ${ }^{6}$ Centro de Investigación Biomédica en Red de Fisiopatología de la Obesidad y Nutrición (CIBERObn), Instituto de Salud Carlos III, Madrid, Spain. ${ }^{7}$ Departamento de Pediatría, Universidad de Zaragoza, Zaragoza, Spain. ${ }^{8}$ Biblioteca General Alfonso Borrero Cabal, Pontificia Universidad Javeriana, Bogotá, Colombia.

Received: 8 February 2021 Accepted: 18 November 2021 Published online: 22 January 2022

\section{References}

1. Weiss R, Bremer AA, Lustig RH. What is metabolic syndrome, and why are children getting it? Ann NY Acad Sci. 2013;1281:123-40.

2. Weiss R, Dziura J, Burgert TS, Tamborlane WV, Taksali SE, Yeckel CW, et al. Obesity and the metabolic syndrome in children and adolescents. N Engl J Med. 2004;350:2362-74.

3. Sharma V, Coleman S, Nixon J, Sharples L, Hamilton-Shield J, Rutter H, et al. A systematic review and meta-analysis estimating the population prevalence of comorbidities in children and adolescents aged 5 to 18 years. Obes Rev. 2019;20:1341-9. https://doi.org/10.1111/obr.12904.

4. Peplies J, Börnhorst C, Günther K, Fraterman A, Russo P, Veidebaum T, et al. Longitudinal associations of lifestyle factors and weight status with insulin resistance (HOMA-IR) in preadolescent children: the large prospective cohort study IDEFICS. Int J Behav Nutr Phys Act. 2016;13:97. https://doi.org/10.1186/s12966-016-0424-4.
5. Zimmet P, Alberti KGMM, Kaufman F, Tajima N, Silink M, Arslanian S, et al. The metabolic syndrome in children and adolescents - an IDF consensus report. Pediatr Diabetes. 2007;8:299-306. https://doi.org/10.1111/j. 1399-5448.2007.00271.x.

6. Magge SN, Goodman E, Armstrong SC. The metabolic syndrome in children and adolescents: shifting the focus to cardiometabolic risk factor clustering. Pediatrics. 2017;140:e20171603. https://doi.org/10.1542/ peds.2017-1603.

7. World Obesity Federation. Atlas of childhood obesity; 2019. p. 213. https://www.worldobesity.org/nlsegmentation/global-atlas-on-child hood-obesity

8. Chung S. Body mass index and body composition scaling to height in children and adolescent. Ann Pediatr Endocrinol Metab. 2015;20:125-9. https://doi.org/10.6065/apem.2015.20.3.125.

9. Bohn B, Müller MJ, Simic-Schleicher G, Kiess W, Siegfried W, Oelert M, et al. BMI or BIA: is body mass index or body fat mass a better predictor of cardiovascular risk in overweight or obese children and adolescents? A German/Austrian/Swiss multicenter APV analysis of 3,327 children and adolescents. Obes Facts. 2015;8:156-65. https://doi.org/10.1159/ 000381227.

10. McCarthy HD, Cole TJ, Fry T, Jebb SA, Prentice AM. Body fat reference curves for children. Int J Obes. 2006;30:598. https://doi.org/10.1038/sj. ijo.0803232

11. Pereira-da-Silva L, Dias MP-G, Dionísio E, Virella D, Alves M, Diamantino $C$, et al. Fat mass index performs best in monitoring management of obesity in prepubertal children. J Pediatr. 2016;92:421-6. https://doi. org/10.1016/j.jped.2015.11.003.

12. Peralta Peña SL, Reséndiz González E, Rubí Vargas M, Terrazas Medina EA, Cupul Uicab LA. Anthropometric indicators and cardiometabolic events among school-aged children from Sonora, Mexico. Nutr Hosp. 2015:32:1483-92. https://doi.org/10.3305/nh.2015.32.4.9560.

13. Wells JCK, Fewtrell MS, Williams JE, Haroun D, Lawson MS, Cole TJ. Body composition in normal weight, overweight and obese children: matched case-control analyses of total and regional tissue masses, and body composition trends in relation to relative weight. Int J Obes. 2006;30:1506-13. https://doi.org/10.1038/sj.ijo.0803402.

14. Debnath S, Mondal N, Sen J. Percent of body fat, fat-mass, fat-free mass and assessment of body composition among rural school-going children of Eastern-India. Anthropol Rev. 2018;81:158. https://doi.org/ 10.2478/anre-2018-0011.

15. Abe T, Patterson KM, Stover CD, Young KC. Influence of adipose tissue mass on DXA-derived lean soft tissue mass in middle-aged and older women. Age (Dordr). 2015;37:9741. https://doi.org/10.1007/ s11357-014-9741-1.

16. Brown LD. Endocrine regulation of fetal skeletal muscle growth: impact on future metabolic health. J Endocrinol. 2014;221:R13-29. https://doi. org/10.1530/JOE-13-0567.

17. Karasik D, Chou W-C, Kiel DP, Hsu Y-H, Amin N, van Duijn CM, et al. Disentangling the genetics of lean mass. Am J Clin Nutr. 2019;109:276-87. https://doi.org/10.1093/ajcn/nqy272.

18. Perreault K, Lagacé J-C, Brochu M, Dionne IJ. Association between fat free mass and glucose homeostasis: common knowledge revisited. Ageing Res Rev. 2016;28:46-61. https://doi.org/10.1016/j.arr.2016.04.007.

19. Liberati A, Altman DG, Tetzlaff J, Mulrow C, Gøtzsche PC, loannidis JPA, et al. The PRISMA statement for reporting systematic reviews and metaanalyses of studies that evaluate healthcare interventions: explanation and elaboration. BMJ. 2009;339. https://doi.org/10.1136/bmj.b2700.

20. Shamseer L, Moher D, Clarke M, Ghersi D, Liberati A, Petticrew M, et al. Preferred reporting items for systematic review and meta-analysis protocols (PRISMA-P) 2015: elaboration and explanation. BMJ. 2015;349. https://doi.org/10.1136/bmj.g7647.

21. Page MJ, McKenzie JE, Bossuyt PM, Boutron I, Hoffmann TC, Mulrow CD, et al. The PRISMA 2020 statement: an updated guideline for reporting systematic reviews. BMJ. 2021:372.

22. McGowan J, Sampson M, Salzwedel DM, Cogo E, Foerster V, Lefebvre C. PRESS peer review of electronic search strategies: 2015 guideline statement. J Clin Epidemiol. 2016;75:40-6. https://doi.org/10.1016/j.jclinepi. 2016.01.021.

23. Bramer WM, Giustini D, De Jonge GB, Holland L, Bekhuis T. De-duplication of database search results for systematic reviews in EndNote. J Med Libr Assoc. 2016;104:240-3. 
24. Gonzalez-Gil AM, Peschard-Franco M, Castillo EC, Gutierrez-Delbosque G, Treviño V, Silva-Platas C, et al. Myokine-adipokine cross-talk: potential mechanisms for the association between plasma irisin and adipokines and cardiometabolic risk factors in Mexican children with obesity and the metabolic syndrome. Diabetol Metab Syndr. 2019;11:1-16.

25. Kim JY, Bacha F, Tfayli H, Michaliszyn SF, Yousuf S, Arslanian S, et al. Adipose tissue insulin resistance in youth on the spectrum from normal weight to obese and from normal glucose tolerance to impaired glucose tolerance to type 2 diabetes. Diabetes Care. 2019;42:265-72. https://doi.org/10.2337/dc18-1178.

26. Masquio DCL, de Piano-Ganen A, Oyama LM, Campos RMDS, Santamarina $A B$, de Souza GIDMH, et al. The role of free fatty acids in the inflammatory and cardiometabolic profile in adolescents with metabolic syndrome engaged in interdisciplinary therapy. J Nutr Biochem. 2016;33:136-44.

27. Rodríguez-Rodríguez E, Palmeros-Exsome C, López-Sobaler AM, Ortega RM, Research G. Preliminary data on the association between waist circumference and insulin resistance in children without a previous diagnosis. Eur J Pediatr. 2011;170:35-43. https://doi.org/10.1007/ s00431-010-1260-1.

28. Sanches PDL, de Mello MT, Fonseca FAH, Elias N, de Piano A, Carnier J, et al. Insulin resistance can impair reduction on carotid intima-media thickness in obese adolescents. Arq Bras Cardiol. 2012;99:892-8.

29. Burrows R, Correa-Burrows P, Reyes M, Blanco E, Albala C, Gahagan S. Healthy Chilean adolescents with HOMA-IR $\geq 2.6$ have increased cardiometabolic risk: association with genetic, biological, and environmental factors. J Diabetes Res. 2015;2015:783296. https://doi.org/10. 1155/2015/783296.

30. Weiss R, Dufour S, Taksali SE, Tamborlane WV, Petersen KF, Bonadonna RC, et al. Prediabetes in obese youth: a syndrome of impaired glucose tolerance, severe insulin resistance, and altered myocellular and abdominal fat partitioning. Lancet. 2003;362:951-7. https://doi.org/10. 1016/S0140-6736(03)14364-4.

31. Brufani C, Grossi A, Fintini D, Fiori R, Ubertini G, Colabianchi D, et al. Cardiovascular fitness, insulin resistance and metabolic syndrome in severely obese prepubertal Italian children. Horm Res Paediatr. 2008;70:349-56.

32. Brufani C, Fintini D, Giordano U, Tozzi AE, Barbetti F, Cappa M. Metabolic syndrome in Italian obese children and adolescents: stronger association with central fat depot than with insulin sensitivity and birth weight. Int J Hypertens. 2011;2011:257168.

33. Hsu YW, Belcher BR, Ventura EE, Byrd-Williams CE, Weigensberg MJ, Davis JN, et al. Physical activity, sedentary behavior, and the metabolic syndrome in minority youth. Med Sci Sports Exerc. 2011;43:2307-13.

34. Weber DR, Leonard MB, Shults J, Zemel BS. A comparison of fat and lean body mass index to BMI for the identification of metabolic syndrome in children and adolescents. J Clin Endocrinol Metab. 2014;99:3208-16. https://doi.org/10.1210/jc.2014-1684

35. Wan X, Wang W, Liu J, Tong T. Estimating the sample mean and standard deviation from the sample size, median, range and/or interquartile range. BMC Med Res Methodol. 2014;14:1-13.

36. Blaxter M. Criteria for the evaluation of qualitative research papers. Med Sociol News. 1996;22:68-71.

37. Tooth L, Ware R, Bain C, Purdie DM, Dobson A. Quality of reporting of observational longitudinal research. Am J Epidemiol. 2005;161:280-8. https://doi.org/10.1093/aje/kwi042.

38. Higgins JPT, Altman DG, Gøtzsche PC, Jüni P, Moher D, Oxman AD, et al. The Cochrane Collaboration's tool for assessing risk of bias in randomised trials. BMJ. 2011;343:d5928. https://doi.org/10.1136/bmj. d5928.

39. Higgins JPT, Thomas J, Chandler J, Cumpston M, Li T, Page MJ, et al. Cochrane handbook for systematic reviews of interventions. England: Wiley; 2019

40. GRADEpro GDT. GRADEpro guideline development tool [software]. Canadá: McMaster Univ; 2015. p. 435.

41. Higgins JPT, Thompson SG, Deeks JJ, Altman DG. Measuring inconsistency in meta-analyses. BMJ. 2003;327:557. https://doi.org/10.1136/bmj. 327.7414.557.

42. Peters JL, Sutton AJ, Jones DR, Abrams KR, Rushton L. Comparison of two methods to detect publication bias in meta-analysis. JAMA 2006;295:676-80. https://doi.org/10.1001/jama.295.6.676.
43. Begg CB, Mazumdar M. Operating characteristics of a rank correlation test for publication bias. Biometrics. 1994;50:1088-101. https://doi.org/ $10.2307 / 2533446$

44. Marwitz SE, Gaines MV, Brady SM, Mi SJ, Broadney MM, Yanovski SZ, et al. Cross-sectional and longitudinal examination of insulin sensitivity and secretion across puberty among non-hispanic black and white children. Endocrinol Metab. 2021;35:847-57.

45. Nassis GP, Papantakou K, Skenderi K, Triandafillopoulou M, Kavouras SA, Yannakoulia M, et al. Aerobic exercise training improves insulin sensitivity without changes in body weight, body fat, adiponectin, and inflammatory markers in overweight and obese girls. Metabolism. 2005:54:1472-9.

46. Shaibi GQ, Cruz ML, Ball GDC, Weigensberg MJ, Salem GJ, Crespo NC, et al. Effects of resistance training on insulin sensitivity in overweight Latino adolescent males. Med Sci Sports Exerc. 2006;38:1208-15.

47. Carrel AL, Clark RR, Peterson SE, Nemeth BA, Sullivan J, Allen DB. Improvement of fitness, body composition, and insulin sensitivity in overweight children in a school-based exercise program: a randomized, controlled study. Arch Pediatr Adolesc Med. 2005;159:963-8.

48. Steffen LM, Jacobs DR, Murtaugh MA, Moran A, Steinberger J, Hong $C P$, et al. Whole grain intake is associated with lower body mass and greater insulin sensitivity among adolescents. Am J Epidemiol. 2003;158:243-50.

49. Schmitz KH, Jacobs DR, Hong C-P, Steinberger J, Moran A, Sinaiko AR. Association of physical activity with insulin sensitivity in children. Int J Obes. 2002;26:1310-6. https://doi.org/10.1038/sj.ijo.0802137.

50. Kim ES, Im JA, Kim KC, Park JH, Suh SH, Kang ES, et al. Improved insulin sensitivity and adiponectin level after exercise training in obese Korean youth. Obesity. 2007;15:3023-30.

51. Cruz ML, Bergman RN, Goran MI. Unique effect of visceral fat on insulin sensitivity in obese Hispanic children with a family history of type 2 diabetes. Diabetes Care. 2002;25:1631 LP-636. https://doi.org/10.2337/ diacare.25.9.1631.

52. Van Der Heijden GJ, Wang ZJ, Chu Z, Toffolo G, Manesso E, Sauer PJJ, et al. Strength exercise improves muscle mass and hepatic insulin sensitivity in obese youth. Med Sci Sports Exerc. 2010;42:1973-80.

53. Schwartz B, Jacobs DR, Morgan A, Sreinberger J, Hong C-P, Sinaiko AR. Measurement of insulin sensitivity in children. Diabetes Care. 2008;31:783-8.

54. Huang T, Johnson MS, Goran M. Development of a prediction equation for insulin sensitivity from anthropometry and fasting insulin in prepubertal and early pubertal children. Diabetes Care. 2002;25(7):1203-10.

55. Aeberli I, Jung A, Murer SB, Wildhaber J, Wildhaber-Brooks J, Knöpfli $\mathrm{BH}$, et al. During rapid weight loss in obese children, reductions in TSH predict improvements in insulin sensitivity independent of changes in body weight or fat. J Clin Endocrinol Metab. 2010;95:5412-8.

56. Brufani C, Tozzi A, Fintini D, Ciampalini P, Grossi A, Fiori R, et al. Sexual dimorphism of body composition and insulin sensitivity across pubertal development in obese Caucasian subjects. Eur J Endocrinol. 2009;160:769-75.

57. Goran MI, Shaibi GQ, Weigensberg MJ, Davis JN, Cruz ML. Deterioration of insulin sensitivity and beta-cell function in overweight Hispanic children during pubertal transition: a longitudinal assessment. Int J Pediatr Obes. 2006;1:139-45.

58. Bunt JC, Salbe AD, Harper IT, Hanson RL, Tataranni PA. Weight, adiposity, and physical activity as determinants, of an insulin sensitivity index in Pima Indian children. Diabetes Care. 2003;26:2524-30.

59. Goran MI, Coronges K, Bergman RN, Cruz ML, Gower BA. Influence of family history of type 2 diabetes on insulin sensitivity in prepubertal children. J Clin Endocrinol Metab. 2003;88:192-5.

60. Shaw M, Savoye M, Cali A, Dziura J, Tamborlane WV, Caprio S. Effect of a successful intensive lifestyle program on insulin sensitivity and glucose tolerance in obese youth. Diabetes Care. 2009;32:45-7.

61. Maffeis C, Manfredi R, Trombetta M, Sordelli S, Storti M, Benuzzi T, et al. Insulin sensitivity is correlated with subcutaneous but not visceral body fat in overweight and obese prepubertal children. J Clin Endocrinol Metab. 2008;93:2122-8.

62. Rosenbaum M, Nonas C, Weil R, Horlick M, Fennoy I, Vargas I, et al. School-based intervention acutely improves insulin sensitivity and decreases inflammatory markers and body fatness in junior high school students. J Clin Endocrinol Metab. 2007:92:504-8. 
63. Cisneros-Tapia R, Navarrete FA, Gallegos AC, Robles-Sardin AE, Méndez $\mathrm{RO}$, Valencia ME. Insulin sensitivity and associated risk factors in Mexican children and adolescents. Diabetes Care. 2005;28:2546-7.

64. Eisenmann JC, Dubose KD, Donnelly JE. Fatness, fitness, and insulin sensitivity among 7- to 9-year-old children. Obesity. 2007;15:2135-44.

65. Küçük Yetgin M, Agopyan A, Küçükler FK, Gedikbaşı A, Yetgin S, Çelik Kayapınar F, et al. The effects of resistance and aerobic exercises on adiponectin, insulin resistance, lipid profile and body composition in adolescent boys with obesity. Istanbul Med J. 2020:21:182-9.

66. Gamboa-Gómez Cl, Guerrero-Romero F, Aradillas-García C, Rodríguez-Morán M, Simental-Mendía LE. The fat-to-lean mass ratio is associated with hyperinsulinemia in healthy Mexican adolescents. J Am Coll Nutr. 2021;40:219-23. https://doi.org/10.1080/07315724. 2020.1752845.

67. Kang Y, Park S, Kim S, Koh H. Handgrip strength among Korean adolescents with metabolic syndrome in 2014-2015. J Clin Densitom. 2020;23:271-7. https://doi.org/10.1016/j.jocd.2018.09.002.

68. Vasconcellos F, Cunha FA, Gonet DT, Farinatti PTV. Does recreational soccer change metabolic syndrome status in obese adolescents? A pilot study. Res Q Exerc Sport. 2021;92:91-9. https://doi.org/10.1080/ 02701367.2019.1711007.

69. Šebeková K, Gurecká R, Csongová M, Koborová I, Šebek J. Elevated blood pressure-associated cardiometabolic risk factors and biomarkers in 16-23 years old students with or without metabolic abnormalities. J Hum Hypertens. 2021;35:37-48.

70. Durá-Travé T, Gallinas-Victoriano F, Peñafiel-Freire DM, UrretavizcayaMartinez M, Moreno-González P, Chueca-Guindulain MJ. Hypovitaminosis $D$ and cardiometabolic risk factors in adolescents with severe obesity. Children. 2020;7:10

71. Labayen I, Medrano M, Arenaza L, Máz E, Osés M, Martínez-Vizcáno V, et al. Effects of exercise in addition to a family-based lifestyle intervention program on hepatic fat in children with overweight. Diabetes Care. 2020:43:306-13.

72. Morelli C, Avolio E, Galluccio A, Caparello G, Manes E, Ferraro S, et al. Impact of vigorous-intensity physical activity on body composition parameters, lipid profile markers, and Irisin levels in adolescents: a cross-sectional study. Nutrients. 2020;12(3):742.

73. Haapala EA, Wiklund P, Lintu N, Tompuri T, Väistö J, Finni T, et al. Cardiorespiratory fitness, physical activity, and insulin resistance in children. 2020.

74. Chynoweth J, Hosking J, Jeffery A, Pinkney J. Contrasting impact of androgens on male and female adiposity, fat distribution and insulin resistance in childhood and adolescence (EarlyBird 75). Pediatr Obes. 2020;15:1-13.

75. Cordellat A, Padilla B, Grattarola P, García-Lucerga C, Crehuá-Gaudiza $E$, Núñez F, et al. Multicomponent exercise training combined with nutritional counselling improves physical function, biochemical and anthropometric profiles in obese children: a pilot study. Nutrients. 2020;12:1-15

76. Leone A, Vizzuso S, Brambilla P, Mameli C, Ravella S, De Amicis R, et al. Evaluation of different adiposity indices and association with metabolic syndrome risk in obese children: is there a winner? Int J Mol Sci. 2020;21:1-14.

77. Mayerhofer E, Ratzinger F, Kienreich NE, Stiel A, Witzeneder N, Schrefl $E$, et al. A multidisciplinary intervention in childhood obesity acutely improves insulin resistance and inflammatory markers independent from body composition. Front Pediatr. 2020;8:52.

78. Kim JY, Tfayli H, Bacha F, Lee SJ, Michaliszyn SF, Yousuf S, et al. $\beta$-cell function, incretin response, and insulin sensitivity of glucose and fat metabolism in obese youth: relationship to OGTT-time-to-glucosepeak. Pediatr Diabetes. 2020;21:18-27.

79. Kim J, Son WM, Headid RJ, Pekas EJ, Noble JM, Park SY. The effects of a 12-week jump rope exercise program on body composition, insulin sensitivity, and academic self-efficacy in obese adolescent girls. J Pediatr Endocrinol Metab. 2020;33:129-37.

80. Faria F, Howe C, Faria R, Andaki A, Marins JC, Amorim PR. Impact of recreational sports activities on metabolic syndrome components in adolescents. Int J Environ Res Public Health. 2020;17.

81. Ubago-Guisado E, Gracia-Marco L, Medrano M, Cadenas-Sanchez C, Arenaza L, Migueles $\mathrm{JH}$, et al. Differences in areal bone mineral density between metabolically healthy and unhealthy overweight/obese children: the role of physical activity and cardiorespiratory fitness. Pediatr Res. 2020;87:1219-25. https://doi.org/10.1038/s41390-019-0708-x.
82. Rognvaldsdottir V, Brychta RJ, Hrafnkelsdottir SM, Chen KY, Arngrimsson SA, Johannsson E, et al. Less physical activity and more varied and disrupted sleep is associated with a less favorable metabolic profile in adolescents. PLoS One. 2020;15:1-15.

83. Kondakis K, Kondakis M, Androutsos O, de Henauw S, González-Gross M, Moreno LA, et al. Cardiorespiratory fitness is associated with body composition and insulin resistance in european adolescents: heleNa study. J Sports Med Phys Fitness. 2020;60:1349-57.

84. Duft RG, Castro A, Bonfante ILP, Lopes WA, da Silva LR, Chacon-Mikahil MPT, et al. Altered metabolomic profiling of overweight and obese adolescents after combined training is associated with reduced insulin resistance. Sci Rep. 2020;10:1-11. https://doi.org/10.1038/s41598-020-73943-y.

85. Bozbulut R, Ertaş-Öztürk Y, Döğer E, Bideci A, Köksal E. Increased obesity awareness and adherence to healthy lifestyle-diet reduce metabolic syndrome risk in overweight children. J Am Coll Nutr. 2020;39:432-7. https://doi.org/10.1080/07315724.2019.1691951.

86. Videira-Silva A, Freira S, Fonseca H. Metabolically healthy overweight adolescents: definition and components. Ann Pediatr Endocrinol Metab. 2020;25:256-64.

87. Regecová V, Bališ P, Gerová Z. The role of somatic characteristics in the assessment of cardiometabolic risk in adolescents. Cardiol Lett. 2020;29:138-47.

88. Preuss HG, Kaats GR, Mrvichin N, Aruoma Ol, Bagchi D. Interplay between insulin resistance and body fat mass in evolution of perturbations linked to the metabolic syndrome in non-diabetics: emphasis on inflammatory factors. J Am Coll Nutr. 2020;40:43-52. https://doi.org/10. 1080/07315724.2020.1792376.

89. World Congress on Osteoporosis, Osteoarthritis and Musculoskeletal Diseases (WCO-IOF-ESCEO 2020): Poster Abstracts. Osteoporos Int. 2020;31(Suppl 1):133-621.https://doi.org/10.1007/s00198-020-05696-3.

90. Xiao P, Cheng H, Yan Y, Liu J, Zhao X, Li H, et al. High BMI with adequate lean mass is not associated with cardiometabolic risk factors in children and adolescents. J Nutr. 2021;151:1213-21.

91. Kuk JL, Lee S. Assessing the utility of cardiorespiratory fitness, visceral fat, and liver fat in predicting changes in insulin sensitivity beyond simple changes in body weight after exercise training in adolescents. Appl Physiol Nutr Metab. 2021;46:55-62.

92. Conterato EV, Machado TD, Nogueira-de-Almeida CA, Mello ED. Leptin levels, basal metabolic rates, and insulin resistance in obese pubertal children. Int J Nutrol. 2020;13:017-23.

93. Agostinis-Sobrinho C, Vicente SEDCF, Kievišienè J, Lopes L, Dâmaso AR, Norkiene S, et al. High levels of adiponectin attenuate the detrimental association of adiposity with insulin resistance in adolescents. Nutr Metab Cardiovasc Dis. 2020;30:822-8.

94. Brand C, Martins CMDL, Lemes VB, Pessoa MLF, Dias AF, Cadore EL, et al. Effects and prevalence of responders after a multicomponent intervention on cardiometabolic risk factors in children and adolescents with overweight/obesity: action for health study. J Sports Sci. 2020;38:68291. https://doi.org/10.1080/02640414.2020.1725384.

95. Vitery RJ, Ortega G, Salazar CB. Dimorfismo sexual de la leptina, resistencia a la insulina y composición corporal en prepúberes normopeso. Rev Chil Pediatría. 2020;91:924-9.

96. Dave C, Agarwal N, Patel R, Shukla R, Bajpai A. Predictors of metabolic complications in obese Indian children and adolescents. Indian J Pediatr. 2021;88:252-6.

97. Brand C, Gaya ACA, Dias AF, Agostinis-Sobrinho C, Farinha JB, Boeno FP, et al. Relationship between insulin resistance and adipocytokines: the mediator role of adiposity in children. Ann Hum Biol. 2020;47:244-9. https://doi.org/10.1080/03014460.2020.1740320.

98. Goran MI, Bergman RN, Avila Q, Watkins M, Ball GDC, Shaibi GQ, et al. Impaired glucose tolerance and reduced $\beta$-cell function in overweight Latino children with a positive family history for type 2 diabetes. J Clin Endocrinol Metab. 2004;89:207-12.

99. Behrooz M, Vaghef-Mehrabany E, Moludi J, Ostadrahimi A. Are spexin levels associated with metabolic syndrome, dietary intakes and body composition in children? Diabetes Res Clin Pract. 2021;172:108634. https://doi.org/10.1016/j.diabres.2020.108634.

100. Burrows R, Correa-Burrows P, Reyes M, Blanco E, Albala C, Gahagan S. Low muscle mass is associated with cardiometabolic risk regardless of nutritional status in adolescents: a cross-sectional study in a Chilean birth cohort. Pediatr Diabetes. 2017;18:895-902. 
101. Lee J-W, Lee D-C, Im J-A, Shim J-Y, Kim S-M, Lee H-R. Insulin resistance is associated with arterial stiffness independent of obesity in male adolescents. Hypertens Res. 2007;30:5. https://doi.org/10.1291/hypres.30.5.

102. Ventura EE, Lane CJ, Weigensberg MJ, Toledo-Corral CM, Davis JN, Goran MI. Persistence of the metabolic syndrome over 3 annual visits in overweight Hispanic children: association with progressive risk for type 2 diabetes. $J$ Pediatr. 2009;155:535-541.e1. https://doi.org/10.1016/j.jpeds.2009.04.008.

103. Tsang TW, Kohn M, Chin MC, Singh MF. A randomized controlled trial of Kung Fu training for metabolic health in overweight/obese adolescents: the "martial fitness" study. J Pediatr Endocrinol Metab. 2009;22:595-607.

104. Passariello CL, Gruodyte R, Hiio K, Mäestu J, Jürimäe J, Saar M, et al. ADIPOQ SNP45 associated with lean body mass in physically active normal weight adolescent girls. Am J Hum Biol. 2010;22:813-8.

105. Fu J, Han L, Zhao Y, Li G, Zhu Y, Li Y, et al. Vitamin D levels are associated with metabolic syndrome in adolescents and young adults: the BCAMS study. Clin Nutr. 2019;38:2161-7.

106. Cioffi CE, Alvarez JA, Welsh JA, Vos MB. Truncal-to-leg fat ratio and cardiometabolic disease risk factors in US adolescents: NHANES 20032006. Pediatr Obes. 2019;14:1-9.

107. Kim S-H, Ahn MB, Cho WK, Cho KS, Jung MH, Suh B-K. The relation of serum nesfatin-1 level with anthropometric and metabolic parameters in children and adolescents A prospective observational study. Medicine (Baltimore). 2019;98(19):e15460.

108. Hetherington-Rauth M, Bea JW, Blew RM, Funk JL, Lee VR, Roe DJ, et al. Relationship of cardiometabolic risk biomarkers with DXA and PQCT bone health outcomes in young girls. Bone. 2019;120:452-8.

109. Remor JM, Lopes WA, Locateli JC, Oliveira RP, Simões CF, Barrero CAL, et al. Prevalence of metabolically healthy obese phenotype and associated factors in south American overweight adolescents: a crosssectional study. Nutrition. 2019;60:19-24.

110. Farr C, Middlebrooke AR, Armstrong N, Barker AR, Fulford J, Mawson $\mathrm{DM}$, et al. Objectively measured aerobic fitness is not related to vascular health outcomes and cardiovascular disease risk in 9-10 year old children. J Sports Sci Med. 2019;18:513-22

111. Pollock NK, Bernard PJ, Gutin B, Davis CL, Zhu H, Dong Y. Adolescent obesity, bone mass, and cardiometabolic risk factors. J Pediatr. 2011;158:727-34. https://doi.org/10.1016/j.jpeds.2010.11.052.

112. Dring KJ, Cooper SB, Morris JG, Sunderland C, Foulds GA, Pockley AG, et al. Multi-stage fitness test performance, $(V)$ over dotO(2) peak and adiposity: effect on risk factors for cardio-metabolic disease in adolescents. Front Physiol. 2019;10:629.

113. Denova-Gutiérrez E, Muñoz-Aguirre P, López D, Flores $M$, Medeiros $M$, Tamborrel N, et al. Low serum vitamin D concentrations are associated with insulin resistance in Mexican children and adolescents. Nutrients. 2019;11. https://doi.org/10.3390/nu11092109.

114. Väistö J, Haapala EA, Viitasalo A, Schnurr TM, Kilpeläinen TO, Karjalainen $P$, et al. Longitudinal associations of physical activity and sedentary time with cardiometabolic risk factors in children. Scand J Med Sci Sport. 2019:29:113-23.

115. Rothermel J, Lass N, Barth A, Reinehr T. Link between omentin-1, obesity and insulin resistance in children: findings from a longitudinal intervention study. Pediatr Obes. 2020;15:1-8.

116. Jones A, Hauser J, Karunakaran A, Drechsler K, Taylor A, Muthurangu V, et al. P3419 independent effects of visceral, subcutaneous and liver fat, and fat-free mass on cardiometabolic risk factors in teenagers. Eur Heart J. 2019;40(Supplement_1):3419.

117. Rohrer TR, Rizzo VF, Cäsar JJ, Muelbredt O, Sprengart S, Gortner L, et al. Changes in hepatic risk factors, metabolic variables, body composition, and physical fitness in obese children after a one-year weight loss program. J Pediatr Endocrinol Metab. 2008;21:837-45.

118. Ayvaz DNÇ, Kilinç FN, Paç FA, Cakal E. Anthropometric measurements and body composition analysis of obese adolescents with and without metabolic syndrome. Turkish J Med Sci. 2011;41:267-74.

119. Nişanci-Kilinç F, Çăgdaş DN. Diet and physical activity interventions do have effects on body composition and metabolic syndrome parameters in overweight and obese adolescents and their mothers. Turk J Pediatr. 2013;55:292-9.

120. Hetherington-Rauth M, Bea JW, Blew RM, Funk JL, Lee VR, Varadi TC, et al. Effect of cardiometabolic risk factors on the relationship between adiposity and bone mass in girls. Int J Obes. 2018;42:1185-94. https:// doi.org/10.1038/s41366-018-0134-x
121. Bell LM, Watts K, Siafarikas A, Thompson A, Ratnam N, Bulsara M, et al. Exercise alone reduces insulin resistance in obese children independently of changes in body composition. J Clin Endocrinol Metab. 2007;92:4230-5

122. Kim JH, Park YS. Low muscle mass is associated with metabolic syndrome in Korean adolescents: the Korea National Health and Nutrition Examination Survey 2009-2011. Nutr Res. 2016;36:1423-8. https://doi. org/10.1016/j.nutres.2016.09.013.

123. Dâmaso AR, de Piano A, Campos RM, Corgosinho FC, Siegfried W, Caranti DA, et al. Multidisciplinary approach to the treatment of obese adolescents: effects on cardiovascular risk factors, inflammatory profile, and neuroendocrine regulation of energy balance. Int J Endocrinol. 2013;2013. https://doi.org/10.1155/2013/541032.

124. Toledo-Corral CM, Ventura EE, Hodis HN, Weigensberg MJ, Lane CJ, Li $\mathrm{Y}$, et al. Persistence of the metabolic syndrome and its influence on carotid artery intima media thickness in overweight Latino children. Atherosclerosis. 2009;206:594-8.

125. Bacha F, Bartz SK, Puyau M, Adolph A, Sharma S. Metabolic flexibility across the spectrum of glycemic regulation in youth. JCI Insight. 2021;6:1-10.

126. Jensen RB, Bytoft B, Lohse Z, Johnsen SK, Nielsen MF, Oturai PS, et al. Impact of lean body mass and insulin sensitivity on the IGF-1-bone mass axis in adolescence: the EPICOM study. J Clin Endocrinol Metab. 2021;106:E772-81.

127. Karimi F, Ranjbar Omrani G, Dabbaghmanesh MH. Insulin resistance and bone health in adolescents. Arch Osteoporos. 2021;16(1):1-9.

128. Ong YY, Huang JY, Michael N, Sadananthan SA, Yuan WL, Chen LW, et al. Cardiometabolic profile of different body composition phenotypes in children. J Clin Endocrinol Metab. 2021;106:e2015-24.

129. Sauder KA, Perng W, Palumbo MP, Bloemsma LD, Carey J, Glueck DH, et al. Fat mass accretion from birth to 5 years and metabolic homeostasis in childhood: the healthy start study. J Clin Endocrinol Metab. 2021;106:1684-91.

130. Garfein J, Flannagan KS, Gahagan S, Burrows R, Lozoff B, Villamor E. Vitamin D status in infancy and cardiometabolic health in adolescence. Am J Clin Nutr. 2021;113:104-12.

131. Moulin-Mares SRA, Oliosa PR, Faria ER, Zago-Gomes MP, Mill JG. Association of uric acid with cardiovascular risk in Brazilian children and adolescents. Nutr Metab Cardiovasc Dis. 2021;31:314-21. https://doi. org/10.1016/j.numecd.2020.09.012.

132. Jaksic M, Martinovic M, Gligorovic-Barhanovic N, Antunovic T, Nedovic-Vukovic M. Relationship between insulin-like growth factor-1, insulin resistance and metabolic profile with pre-obesity and obesity in children. J Pediatr Endocrinol Metab. 2021;34:301-9. https://doi.org/10.1515/jpem-2020-0447.

133. Khammassi M, Isacco L, Pereira B, Damaso AR, Matlosz P, Maruszczak K, et al. Cardiometabolic efficacy of multidisciplinary weight loss interventions is not altered in adolescents with obesity initially diagnosed or with a persistent metabolic syndrome. Nutr Res. 2021;86:79-87. https:// doi.org/10.1016/j.nutres.2020.12.008.

134. Niu Y, Zhao X, He H, Mao X, Sheng J, Zou J, et al. The effect of different adiposity factors on insulin resistance in obese children and adolescents. Clin Endocrinol. 2021;94:949-55. https://doi.org/10.1111/cen.14435.

135. Hussid MF, Cepeda FX, Jordão CP, Lopes-Vicente RRP, Virmondes L, Katayama KY, et al. Obesidade Visceral e Hipertensão Sistólica como Substratos da Disfunção Endotelial em Adolescentes Obesos. Arq Bras Cardiol. 2021;116:795-803.

136. Orsso CE, Tibaes JRB, Oliveira CLP, Rubin DA, Field CJ, Heymsfield SB, et al. Low muscle mass and strength in pediatrics patients: why should we care? Clin Nutr. 2019;38:2002-15.

137. Buckinx F, Landi F, Cesari M, Fielding RA, Visser M, Engelke $K$, et al. Pitfalls in the measurement of muscle mass: a need for a reference standard. J Cachexia Sarcopenia Muscle. 2018;9:269-78. https://doi.org/10.1002/ jcsm. 12268.

138. Al-Sallami HS, Goulding A, Grant A, Taylor R, Holford N, Duffull SB. Prediction of fat-free mass in children. Clin Pharmacokinet. 2015;54:1169-78.

139. Gutch M, Kumar S, Razi SM, Gupta KK, Gupta A. Assessment of insulin sensitivity/resistance. Indian J Endocrinol Metab. 2015;19:160-4. https:// doi.org/10.4103/2230-8210.146874

140. Beguinot F, Nigro C. Measurement of glucose homeostasis in vivo: glucose and insulin tolerance tests. In: Joost HG., Al-Hasani H., Schürmann A. (eds) Animal Models in Diabetes Research. Methods in Molecular Biology (Methods and Protocols). Totowa: Humana Press; 2012. vol 933. https://doi.org/10.1007/978-1-62703-068-7_14. 
141. Kyle UG, Schutz Y, Dupertuis YM, Pichard C. Body composition interpretation: contributions of the fat-free mass index and the body fat mass index. Nutrition. 2003;19:597-604.

142. Brochu M, Mathieu ME, Karelis AD, Doucet É, Lavoie ME, Garrel D, et al. Contribution of the lean body mass to insulin resistance in postmenopausal women with visceral obesity: a Monet study. Obesity. 2008:16:1085-93.

143. Sese M, Moreno LA, Censi L, Bresidenassel C, González-Gross M, Sjöström M, et al. Asociación de índices de composición corporal con resistencia a la insulina en adolescentes europeos: El estudio HELENA. Nutr Hosp. 2016;33:533-9.

144. Yang J. Enhanced skeletal muscle for effective glucose homeostasis. 1st ed: Elsevier Inc.; 2014. https://doi.org/10.1016/B978-0-12-800101-1. 00005-3.

145. Sears B, Perry M. The role of fatty acids in insulin resistance. Lipids Health Dis. 2015;14:1-9. https://doi.org/10.1186/s12944-015-0123-1.

146. Ferreira I, Snijder MB, Twisk JWR, Van Mechelen W, Kemper HCG, Seidell $\mathrm{JC}$, et al. Central fat mass versus peripheral fat and lean mass: opposite (adverse versus favorable) associations with arterial stiffness? The Amsterdam growth and health longitudinal study. J Clin Endocrinol Metab. 2004;89:2632-9.

147. Ortega FB, Ruiz JR, Castillo MJ, Sjöström M. Physical fitness in childhood and adolescence: a powerful marker of health. Int J Obes. 2007;32:1 https://doi.org/10.1038/s.i.jo.0803774.

148. You T, Ryan AS, Nicklas BJ. The metabolic syndrome in obese postmenopausal women: relationship to body composition, visceral fat, and inflammation. J Clin Endocrinol Metab. 2004:89:5517-22.

149. Mesinovic J, McMillan LB, Shore-Lorenti C, De Courten B, Ebeling PR, Scott D. Metabolic syndrome and its associations with components of sarcopenia in overweight and obese older adults. J Clin Med. 2019:8:145. https://doi.org/10.3390/jcm8020145.

150. Lagacé JC, Brochu M, Dionne IJ. A counterintuitive perspective for the role of fat-free mass in metabolic health. J Cachexia Sarcopenia Muscle. 2020;11:343-7.

151. Prado CMM, Heymsfield SB. Lean tissue imaging: a new era for nutritional assessment and intervention. J Parenter Enter Nutr. 2014;38:940-53.

152. Friend A, Craig L, Turner S. The prevalence of metabolic syndrome in children: a systematic review of the literature. Metab Syndr Relat Disord. 2013;11:71-80. https://doi.org/10.1089/met.2012.0122.

153. De Lorenzo A. Comparison of different techniques to measure body composition in moderately active adolescents. Br J Sports Med. 1998:32:215-9.

154. Berges GL, Llorente ÁM, Bruton AG, Agüero AG, Rodríguez GV, Casajús JA. Body fat percentage comparisons between four methods in young football players: are they comparable? Nutr Hosp. 2017;34:1119-24.

155. Wells JCK, Cole TJ, team A study. Adjustment of fat-free mass and fat mass for height in children aged 8 y. Int J Obes. 2002;26:947. https://doi. org/10.1038/sj.ijo.0802027.

\section{Publisher's Note}

Springer Nature remains neutral with regard to jurisdictional claims in published maps and institutional affiliations.

Ready to submit your research? Choose BMC and benefit from:

- fast, convenient online submission

- thorough peer review by experienced researchers in your field

- rapid publication on acceptance

- support for research data, including large and complex data types

- gold Open Access which fosters wider collaboration and increased citations

- maximum visibility for your research: over 100M website views per year

At BMC, research is always in progress.

Learn more biomedcentral.com/submissions 